\title{
Antimicrobial and antibiofilm activities of Casearia sylvestris extracts from distinct Brazilian biomes against Streptococcus mutans and Candida albicans
}

Sabrina M. Ribeiro ${ }^{1}$, Érick D. O. Fratucelli ${ }^{1}$, Paula C. P. Bueno ${ }^{2,3}$, Marlene Kelly V. de Castro², Amanda Alcalá Francisco ${ }^{2}$, Alberto José Cavalheiro ${ }^{2^{*}}$ and Marlise I. Klein ${ }^{1 *}$ (D)

\begin{abstract}
Background: Dental caries is a biofilm-diet-dependent worldwide public health problem, and approaches against microorganisms in cariogenic biofilms are necessary.

Methods: The antimicrobial and antibiofilm activities of 12 Casearia sylvestris extracts $(0.50 \mathrm{mg} / \mathrm{mL})$ from different Brazilian biomes (Atlantic Forest, Cerrado, Caatinga, Pampa, and Pantanal) and varieties (sylvestris, lingua, and intermediate) were tested against two species found in cariogenic biofilms (Streptococcus mutans and Candida albicans). The extracts effective against $S$. mutans were used to evaluate the "adhesion strength" of this bacterium to the salivary pellicle and initial glucan matrix and the S. mutans-GtfB activity. Also, the antimicrobial activity against $S$. mutans of three fractions (methanol, ethyl acetate, and hexane; $0.25 \mathrm{mg} / \mathrm{mL}$ ) from the extracts was evaluated.
\end{abstract}

Results: Three extracts from the Atlantic Forest variety sylvestris (FLO/SC, GUA/CE, PRE/SP) reduced $\geq 50 \%$ ( $\geq 3$ logs) S. mutans viable population ( $p<0.0001$ vs. vehicle), while two extracts from the same biome and variety (PAC/CE, PRE/SP) decreased $\geq 50 \%$ of the viable counts of $C$. albicans ( $p<0.0001$ vs. vehicle). For $S$. mutans biofilms, three extracts (GUA/CE, PAC/CE, PRE/SP) reduced the biomass by $\geq 91 \%$ ( $p>0.0001$ vs. vehicle) and $100 \%$ of the microbial population ( $p<0.0001$ vs. vehicle). However, for the fungal biofilm, two extracts (PAC/CE, PRE/SP) reduced the viable counts by $\geq 52 \%$ ( $p<0.0001$ vs. vehicle), but none reduced biomass. The extracts with higher antimicrobial and antibiofilm activities presented higher content of clerodane-type diterpenes and lower content of glycosylated flavonoids than the less active extracts. The extracts had no effect on the removal of cells adhered to the pellicle ( $p>0.05$ vs. vehicle) while promoted the detachment of a larger number of $S$. mutans cells from GtfB-glucan matrix ( $p<0.0031$ vs. vehicle), and FLO/SC, GUA/CE and PRE/SP reduced the quantity of glucans ( $p \leq 0.0136$ vs. vehicle). Only the ethyl acetate fractions reduced the microbial population of $S$. mutans ( $p<0.0001$ vs. vehicle), except for one (PAC/CE). Among the ethyl acetate fractions, three from var. lingua (two from Cerrado, and one from Cerrado/ Caatinga) reduced $\geq 83 \%$ of the microbial population.

(Continued on next page)

\footnotetext{
* Correspondence: alberto.j.cavalheiro@unesp.br; mklein@foar.unesp.br; marlise.klein@unesp.br

${ }^{2}$ Department of Organic Chemistry, São Paulo State University, Rua Prof. Francisco Degni 55, Araraquara, São Paulo 14800-060, Brazil

1 Department of Dental Materials and Prosthodontics, São Paulo State

University (UNESP), School of Dentistry, Rua Humaitá, 1680. Araraquara, Sao

Paulo 14801-903, Brazil

Full list of author information is available at the end of the article
}

(c) The Author(s). 2019 Open Access This article is distributed under the terms of the Creative Commons Attribution 4.0 International License (http://creativecommons.org/licenses/by/4.0/), which permits unrestricted use, distribution, and reproduction in any medium, provided you give appropriate credit to the original author(s) and the source, provide a link to the Creative Commons license, and indicate if changes were made. The Creative Commons Public Domain Dedication waiver (http://creativecommons.org/publicdomain/zero/1.0/) applies to the data made available in this article, unless otherwise stated. 
(Continued from previous page)

Conclusions: C. sylvestris extracts from Atlantic Forest var. sylvestris and ethyl acetate fractions from Cerrado and

Cerrado/Caatinga var. lingua may be used as a strategy against cariogenic microorganisms.

Keywords: Streptococcus mutans, Candida albicans, Casearia sylvestris, Biofilm

\section{Background}

Dental caries is still the most prevalent oral condition associated with biofilm in the world [1-3], which harms the quality of life of millions of people [1-3]. This ubiquitous disease results from complex interactions between specific oral organisms, host factors, and diet, which promote the transition from a healthy biofilm to a pathogenic one on the surface of the teeth $[4,5]$. Therefore, approaches to hinder and control the formation of pathogenic biofilms can be a strategy for the prevention of dental caries.

Streptococcus mutans plays a key role in the modulation and transition from non-pathogenic form to highly cariogenic biofilms [6], although additional organisms may be associated [7-9]. This species is highly acidogenic and aciduric and is the main producer of the extracellular matrix in dental biofilms [5]. What makes S. mutans the leading producer of exopolysaccharides is that it encodes multiple exoenzymes, mainly glycosyltransferases (Gtfs) $[5,10]$ that are secreted into the extracellular medium and use dietary sucrose as the substrate to synthesize glucans. Gtfs become constituents of the salivary pellicle and are also adsorbed to the surfaces of $S$. mutans and other microorganisms, such as Candida albicans, maintaining its enzymatic activity $[5,11$, 12]. Glucan synthesis in the pellicle provides additional microbial binding sites, while the polymers on the surface of microorganisms increase the cohesion between organisms $[5,11,12]$.

C. albicans is the fungus most commonly found on human mucosal surfaces and frequently participates in the formation of polymicrobial biofilms on biotic and abiotic surfaces [13, 14], especially in the presence of dietary sucrose [15]. This fungus has an extraordinary acidogenic capacity and acid tolerance, and its association with $S$. mutans results in increased exopolysaccharides formation, enhancing biofilm cariogenicity [1618]. In addition, $C$. albicans produces and secretes exoenzymes capable of degrading dentin collagen under acidic conditions, contributing to biofilm virulence and cariogenicity $[19,20]$.

Preventing the formation of this biofilm is essential to avoid the occurrence of dental caries. Chlorhexidine (a broad-spectrum antimicrobial agent) and fluoride are considered gold standard in dentistry for biofilm treatment and caries prevention, respectively. However, chlorhexidine suppresses the buccal microbiota [21] and is not suitable for daily and continuous preventive and / or therapeutic use due to its side effects [21], while fluoride provides incomplete protection against disease and has no antimicrobial effect under the conditions clinically used [22].

Therefore, it is necessary to search for strategies to control and/or modulate cariogenic biofilms and, at the same time, do not cause toxicity to the human organism. One attractive approach would be the use and/or inclusion of bioactive agents that affect the virulence of pathogenic microorganisms without unbalancing the normal microbiota of the mouth. Consequently, there is a growing interest of researchers and industry in the development of new therapies based on natural products [23]. These products could be used to reduce biofilm pathogenicity as an adjunct of fluoride for caries prevention.

Natural products have a wide range of activities and functions and have a rich history of use in traditional medicine. The prospection of compounds extracted from plant extracts with antimicrobial properties and antibiofilm is a relevant strategy for dentistry and other areas.

Casearia sylvestris Swartz (Salicaceae) is a plant that is distributed in the tropical and subtropical regions of Brazil, and other countries of South America and Asia. It has a huge pharmacological and cytotoxic arsenal, anti-inflammatory, antiplasmodial, and anti-ulcer properties [24]. C. sylvestris ("guaçatonga") is part of popular/ traditional use in Brazil [24, 25]. This plant is cited in the "National List of Medicinal Plants of Interest to SUS" (RENISUS), which contains 71 species that could treat the diseases with a high incidence in Brazil [25]. Indigenous tribes use the macerated bark of $C$. sylvestris to treat gastrointestinal disorders (i.e., diarrhea), leprosy, snake bites, and to heal wounds [24], while decocted bark is used as an anti-inflammatory [26], and for snake bite where the bark is infused for on-site application [27]. In addition, Brazilian natives use leaves of $C$. sylvestris as tonic and antispasmodic, for fever, syphilis, herpes, and snake bites $[26,28]$. The usual administration is oral, and the most common form of preparation is decoction.

However, there is little elucidation about its antimicrobial activity [29, 30], while its anti-cariogenic biofilm effect is non-existent. The chemical profile of leaf extracts of C. sylvestris var. sylvestris (from Atlantic Forest) presents a rich phytochemical composition, with abundant diterpenes, considered taxonomic markers for this genus 
[31] while phenolic compounds (flavonoids) predominate in var. lingua [32, 33].

Hence, C. sylvestris provides a rich source of molecules that may exhibit antimicrobial and antibiofilm properties. Therefore, the current study evaluated the antimicrobial and antibiofilm activities of $C$. sylvestris leaves extracts and fractions from distinct Brazilian biomes, belonging to varieties lingua, sylvestris, and intermediate. The extracts that presented an antibiofilm response against $S$. mutans were used to verify the effect on the adhesion of this microorganism to the salivary pellicle and the initial matrix (glucans) formed on hydroxyapatite surface.

\section{Methods}

\section{Casearia sylvestris extracts and fractions from distinct Brazilians biomes}

The plant was registered in the National System of Genetic Resource Management and Associated Traditional Knowledge (SisGen; Register \#A00892A) and all collections were made with the permission of the Brazilian Institute of Environment and Renewable Natural Resources (IBAMA) through the System Authorization and Information on Biodiversity (SISBIO), which provided proof of registration (SISBIO; Register \# 33429-1).

The samples were collected from three different individuals of $C$. sylvestris from 12 regions from Brazil, belonging to the biomes: Cerrado, Caatinga, Atlantic Forest, Pampa, and Pantanal, in the period between June and September 2012 and 2013. Voucher specimens of all samples were sent to Agronomic Institute of Campinas (São Paulo State, Brazil) for identity confirmation and variety assignment by Prof. Dr. Roseli B. Torres.
Depending on the availability of plant material, 10 to 20 leaves were collected, and these leaves were dehydrated at $40^{\circ} \mathrm{C}$ in a circulating air oven and stored in hermetically sealed plastic bags at room temperature. Then, these samples were individually ground, and $5 \mathrm{~g}$ of each sample were extracted three times using 30, 15, and $10 \mathrm{~mL}$ portions of extractor solvent (water, ethanol, and isopropyl alcohol, in a proportion of 5:3:2 - \% v/v), using an ultrasonic bath. Between each extraction cycle, these samples were centrifuged (5000 $x g, 5 \mathrm{~min})$ and then filtered. Next, these extracts were combined and lyophilized, resulting in 12 freeze-dried crude extracts (Table 1). Finally, these extracts were solubilized at 6 $\mathrm{mg} / \mathrm{mL}$ with $84.15 \%$ ethanol (EtOH; Sigma-Aldrich Co. St. Louis, MO) and 15\% dimethyl sulfoxide (DMSO; Sigma-Aldrich Co. St. Louis, MO).

The fractions of the crude extracts were obtained as described before [28]. Solid phase extraction cartridges (SPE) containing $1 \mathrm{~g}$ of a mixture of silica gel 40 $63 \mu \mathrm{m}, 60 \AA$ (Merck, Germany) and activated carbon (LABSYNTH, Brazil) (500 mg of each) were prepared. The columns were preconditioned with hexane/ethyl acetate 95:5 (\% v/v; both from J.T. Baker, grade HPLC) and then $150 \mathrm{mg}$ of the samples were applied. Fractions were eluted with $10 \mathrm{~mL}$ of 95:5 (\% v/v) hexane/ethyl acetate (Hex fraction), 100\% ethyl acetate (AcOEt fraction) and $100 \%$ methanol $(\mathrm{MeOH}$ fraction), respectively. Next, the solvents were evaporated with a Speed Vac modelo SPD (Thermo Scientific), resulting in dry fractions for the tests proposed. The fractions were solubilized at $1 \mathrm{mg} / \mathrm{mL}$ with $28 \% \mathrm{EtOH}$ (Sigma-Aldrich Co. St. Louis, MO) and 5\% DMSO (Sigma-Aldrich Co. St. Louis, MO) and $1 \mathrm{X}$ PBS (1x phosphate buffered saline, $\mathrm{pH}$ 7.4).

Table 1 Samples of C. sylvestris collected in different Brazilian biomes. Personal communication by Dr. Paula Carolina Pires Bueno

\begin{tabular}{|c|c|c|c|c|c|c|}
\hline \multirow[t]{2}{*}{ Population $^{a}$} & \multirow{2}{*}{$\begin{array}{l}\text { Sample } \\
\text { Code }\end{array}$} & \multirow[t]{2}{*}{ Morphology ${ }^{b}$} & \multirow[t]{2}{*}{ Biome } & \multicolumn{2}{|l|}{ Climate $^{c}$} & \multirow{2}{*}{$\begin{array}{l}\text { Sun } \\
\text { exposition }\end{array}$} \\
\hline & & & & Temperature $\left({ }^{\circ} \mathrm{C}\right)$ & Precipitation $(\mathrm{mm})$ & \\
\hline Araraquara/SP & ARA/SP & $\mathrm{L}$ & Cerrado & 20.4 & 1352 & High \\
\hline São Roque de Minas/MG & SRM/MG & $L$ & Cerrado & 20.6 & 1390 & High \\
\hline Cariri/CE & CAR/CE & $L$ & Ecotone (Cerrado/Caatinga) & 25.1 & 1086 & High \\
\hline Luis Antônio/SP & LUI/SP & $L$ & Ecotone (Cerrado/Atlantic Forest) & 21.9 & 1508 & High \\
\hline Mogi-Guaçu/SP & MOG/SP & 1 & Ecotone (Cerrado/Atlantic Forest) & 20.3 & 1344 & High \\
\hline Rio Grande/RS & $\mathrm{RIO} / \mathrm{RS}$ & । & Pampa (Cerrado / wetland area) & 18.3 & 1205 & High \\
\hline Cáceres/MT & CAC/MT & 1 & Pantanal (Cerrado / wetland area) ${ }^{d}$ & 26.3 & 1301 & High \\
\hline Campinas/SP & CAM/SP & । & Cerrado (Ciliary Forest) & 19.3 & 1315 & Low \\
\hline Guaramiranga/CE & GUA/CE & S & Atlantic Forest & 20.9 & 1560 & Low \\
\hline Pacoti/CE & $\mathrm{PAC/CE}$ & S & Atlantic Forest & 21.5 & 1524 & Low \\
\hline Florianópolis/SC & $\mathrm{FLO} / \mathrm{SC}$ & $\mathrm{S}$ & Atlantic Forest & 20.1 & 1462 & Low \\
\hline Presidente Venceslau/SP & PRE/SP & $\mathrm{S}$ & Atlantic Forest (remnant area) & 21.6 & 1207 & Low \\
\hline
\end{tabular}

${ }^{a}$ Five or six individuals sampled; ${ }^{b}$ Morphology based on botanical classification; ${ }^{c}$ Climate data corresponds to the average annual values - available at https://pt. climate-data.org/ and http://www.inmet.gov.br; ${ }^{d}$ these localities have high water availability; L: var. lingua; S: var. sy/vestris; I: intermediate morphology 


\section{Chemical characterization of the crude extracts}

The chromatographic analyses used a UHPLC-DAD (Ultimate 3000 RS, Dionex) equipped with a degasser, quaternary pump, automatic sampler, UV photodiode array detector, and oven, following the methodology of Bueno et al. [33]. The separation was achieved using a C18 analytical column (Phenomenex Kinetex $150 \times 2.1 \mathrm{~mm}$, $2.6 \mu \mathrm{m}, 100 \AA$ ) protected by a compatible pre-column. The chromatographic conditions were: flow rate of $400 \mu \mathrm{L} / \mathrm{min}$, column temperature of $35^{\circ} \mathrm{C}$, and injection volume of $2 \mu \mathrm{L}$. The mobile phase consisted of water (A) and acetonitrile (B) using the following linear gradient elution: $10-25 \%$ B from 0 to $15 \mathrm{~min}, 25-90 \%$ B at 35 min, maintaining $90 \% \mathrm{~B}$ until $40 \mathrm{~min}$ and returning to the initial conditions, $10 \% \mathrm{~B}$ over $2 \mathrm{~min}$, and holding for a further $3 \mathrm{~min}$ for column reconditioning. Absorption spectral data were collected within 45 min from 200 to $800 \mathrm{~nm}$ [33].

\section{Microbial strains and growth conditions}

The strains S. mutans UA159 and C. albicans SC5314 were grown on blood agar plates (Laborclin, Brazil) and incubated $\left(48 \mathrm{~h}, 37^{\circ} \mathrm{C}, 5 \% \mathrm{CO}_{2}\right.$; Thermo Scientific, Waltham, USA). These two species were selected as model organisms associated with dental caries development [16]. Five to ten colonies of each microorganism were inoculated in $10 \mathrm{~mL}$ of culture medium tryptone-yeast extract broth [TYE: $2.5 \%(\mathrm{w} / \mathrm{v})$ tryptone with $1.5 \%(\mathrm{w} / \mathrm{v})$ yeast extract, $\mathrm{pH} 7.0$ Difco] containing $1 \%$ glucose $(\mathrm{w} / \mathrm{v})$ (TYEg) and incubated $\left(37^{\circ} \mathrm{C}, 5 \% \mathrm{CO}_{2}\right)$. After $16 \mathrm{~h}$, the starter cultures were diluted (1:20) in TYEg medium, and grown until mid-log growth phase $\left[\mathrm{OD}_{540 \mathrm{~nm}}\right.$ $0.824 \pm 0.169$ and $1.37 \mathrm{E}+09 \pm 6.16 \mathrm{E}+08$ colony forming units per milliliter $(\mathrm{CFU} / \mathrm{mL})$ for S. mutans; $\mathrm{OD}_{540 \mathrm{~nm}}$ $0.967 \pm 0.034$ and $1.96 \mathrm{E}+07 \pm 3.63 \mathrm{E}+06 \mathrm{CFU} / \mathrm{mL}$ for $C$. albicans]. The inoculum for downstream assays were prepared with a defined population of $2 \mathrm{E}+06 \mathrm{CFU} / \mathrm{mL}$ for both strains in TYEg for antimicrobial assessment and TYE with $1 \%$ sucrose (w/v) (TYEs) for biofilms assays.

\section{Antimicrobial activity assay}

Screenings using $0.50 \mathrm{mg} / \mathrm{mL}$ of extracts and $0.25 \mathrm{mg} /$ $\mathrm{mL}$ of fractions were performed on 96-well flat bottom microplates (Kasvi). The concentrations were selected because of the yield of extracts and fractions and based on the literature, which considers that experiments with amounts greater than $1 \mathrm{mg} / \mathrm{mL}$ for extracts or $0.1 \mathrm{mg} /$ $\mathrm{mL}$ for isolated compounds should be avoided [34, 35]. At these working concentrations, the vehicle was $7 \%$ EtOH [36] and 1.25\% DMSO.

A $100 \mu \mathrm{L}$ volume of the microbial inoculum $(2 \mathrm{E}+06$ $\mathrm{CFU} / \mathrm{mL}$ ) prepared with TYEg was transferred to the wells in the microplates. Next, $16.67 \mu \mathrm{L}$ each extract (or its vehicle) or $50 \mu \mathrm{L}$ fraction (or its vehicle) were added into the microbial inoculum plus $83.33 \mu \mathrm{L}$ (for extracts) or $50 \mu \mathrm{L}$ (for fractions) of TYEg to achieve $1 \mathrm{E}+06 \mathrm{CFU} /$ $\mathrm{mL}$ in a total volume of $200 \mu \mathrm{L}$, and the microplates were incubated $\left(24 \mathrm{~h}, 37^{\circ} \mathrm{C}, 5 \% \mathrm{CO}_{2}\right)$. In addition to treatments and vehicle, a microbial growth control without treatment was included; controls per treatment without microbial inoculation were also performed. Each treatment was performed at least in triplicates at four distinct experiments. After $24 \mathrm{~h}$ of incubation, visual inspection of the wells (turbidity: microbial growth, clear: no growth) and $\mathrm{OD}_{562 \mathrm{~nm}}$ readings (ELISA plate reader, Biochrom Ez, Cambourne, UK) were performed. However, both visual inspection data and OD readings were inconsistent because the replicates of the same experiment and from different experiments for treatments and their controls without microbial growth presented high variability; thus, these data were not shown. Attempts to determine the turbidity of cultures with a microplate reader have been reported to have flaws when used for natural compounds (as observed by visual inspection and O.D. readings), as with some test organisms the cells agglomerated at the bottom of the well and, other organisms, the cells remained in suspension [37].

Moreover, the precipitation of compounds present in extracts can generate turbidity of the wells, hindering the interpretation of the data [37]. Thus, these two analyses may not reflect the actual antimicrobial activity of the treatments (especially extracts), since the precipitation of compounds present in extracts can generate turbidity of the wells [37]. Therefore, an aliquot of each well was used for a 10 -fold serial dilution $\left(10^{0}\right.$ to $\left.10^{-5}\right)$ in saline solution $(0.89 \% \mathrm{NaCl}$; Synth) to determine microbial cells viability by plating blood agar plates $(48 \mathrm{~h}$, $37^{\circ} \mathrm{C}$ and $5 \% \mathrm{CO}_{2}$ ). After incubation, the colonies were counted to obtain $\mathrm{CFU} / \mathrm{mL}$ and calculate log and percentage of microbial growth inhibition compared to vehicle control.

\section{Antibiofilm activity assays using single-species biofilm models}

For antibiofilm evaluation, the single concentration of $0.50 \mathrm{mg} / \mathrm{mL}$ of each extract was also used as an initial prospecting study, and the vehicle was also $7 \% \mathrm{EtOH}$ and $1.25 \%$ DMSO. The antibiofilm activity was determined by viable counts of the microbial population $(\mathrm{CFU} / \mathrm{mL})$ and total biomass assessment using singlespecies biofilm models of $S$. mutans and C. albicans. A $100 \mu \mathrm{L}$ volume of the microbial inoculum $(2 \mathrm{E}+06 \mathrm{CFU} /$ $\mathrm{mL}$ ) prepared with TYEs [38] was transferred to the wells in a flat bottom microplate. Next, $16.67 \mu \mathrm{L}$ of extract or vehicle were added into the microbial inoculum plus $83.33 \mu \mathrm{L}$ of TYEs to achieve $1 \mathrm{E}+06 \mathrm{CFU} / \mathrm{mL}$, and the microplates were incubated $\left(24 \mathrm{~h}, 37^{\circ} \mathrm{C}, 5 \% \mathrm{CO}_{2}\right)$. 
As for antimicrobial assay, in addition to treatments and vehicle, a microbial growth control without treatment was included, and controls per treatment without microbial inoculation (to serve as blank controls) were also performed. Each treatment was performed at least in triplicates at four distinct experiments. After $24 \mathrm{~h}$ of incubation, the microplates were placed on an orbital shaker at $75 \mathrm{rpm}$ for $5 \mathrm{~min}$ (Quimis, G816 M20, São Paulo, BR). Next, the culture medium with unbound microbial cells was removed, and remaining biofilms were washed three times, with $0.89 \% \mathrm{NaCl}$ solution to remove non-adhered cells.

\section{Biomass of treated biofilms}

The washed biofilms (and wells with appropriate blank controls with treatments but without microbial inoculation) were stained with an aqueous solution of $1 \%$ violet crystal and incubated $\left(25^{\circ} \mathrm{C}, 35 \mathrm{~min}\right)$. Next, the wells were washed using MilliQ water and air-dried for 60-90 min. Then, the violet crystal was eluted with $99 \% \mathrm{EtOH}$ and incubation during $5 \mathrm{~min}$ on the orbital shaker $\left(37^{\circ} \mathrm{C}, 200 \mathrm{rpm}\right.$; Quimis, G816 M20, São Paulo, BR). Next, $150 \mu \mathrm{L}$ of the eluted volumes were transferred to another microplate, and the $\mathrm{OD}_{570 \mathrm{~nm}}$ was measured on an ELISA plate reader (Biochrom Ez).

\section{Viable counts of the microbial population of treated biofilms}

The washed biofilms (and wells with appropriate blank controls with treatments but without microbial inoculation) were removed from each well using pipette tips and $0.89 \% \mathrm{NaCl}$ solution and transferred to microtubes. Then, an aliquot of each biofilm suspension was used for a 10 -fold serial dilution $\left(10^{0}\right.$ to $\left.10^{-5}\right)$ followed by plating on blood agar plates $\left(48 \mathrm{~h}, 37^{\circ} \mathrm{C}, 5 \% \mathrm{CO}_{2}\right)$. After incubation, the colonies were counted to obtain CFU/ $\mathrm{mL}$ and calculate log and percentage of microbial growth inhibition by each extract, compared to vehicle control.

\section{Effect of selected extracts on the initial formation of the Glucan matrix (GtfB activity) Purification of GtfB}

The GtfB enzyme was purified from the culture supernatant of Streptococcus milleri KSB8, following the published methodology [39, 40]. Purification procedures were performed using buffers containing two protease inhibitors as preservatives [0.1 $\mathrm{mM}$ phenylmethylsulfonyl fluoride (PMSF) and $0.02 \%$ sodium azide $\left.\left(\mathrm{NaN}_{3}\right)\right]$. GtfB was purified using a chromatography column containing hydroxyapatite beads following methodology detailed before [39]. After purification, the enzyme was checked on acrylamide gel (SDS-PAGE) and stained with silver nitrate. Aliquots of the enzyme were stored at $-80{ }^{\circ} \mathrm{C}$ until use.

\section{Salivary pellicle formation}

Hydroxyapatite (HA) beads (Macro-Prep Ceramic Hydroxyapatite Type I $80 \mu \mathrm{m}$; BioRad) were used as the surface for salivary pellicle formation, to mimic the dental enamel. These beads were coated with saliva for acquired pellicle formation (sHA), following a previous protocol [41]. Stimulated whole saliva was obtained from one healthy volunteer, diluted 1:1 with adsorption buffer (AB buffer: $50 \mathrm{mM} \mathrm{KCl}, 1 \mathrm{mM} \mathrm{K \textrm {KO } _ { 4 } , 1 \mathrm { mM } \mathrm { CaCl }} 2,1$ $\mathrm{mM} \mathrm{MgCl} 2,0.1 \mathrm{mM}$ PMSF, in dd- $\mathrm{H}_{2} \mathrm{O}, \mathrm{pH}$ 6.5], centrifuged $\left(1699 \times \mathrm{g}, 20 \mathrm{~min}, 4{ }^{\circ} \mathrm{C}\right.$; Eppendorf, Centrifuge 5810R) and sterilized by filtration $(0.22 \mu \mathrm{m}$ low protein binding polyethersulfone membrane filter) [41]. The Institutional Ethical Committee approved the study (CAAE: 68161417.0.0000.5416).

Aliquots of $500 \mu \mathrm{L}$ of saliva were added to microtubes containing pre-washed (with $\mathrm{AB}$ buffer containing 0.1 $\mathrm{mM}$ PMSF and $0.02 \% \mathrm{NaN}_{3}$ ) and sterilized $\mathrm{HA}$ beads, followed by incubation in a homogenizer $\left(40 \mathrm{~min}, 37^{\circ} \mathrm{C}\right.$, $24 \mathrm{rpm}$; Fisher Scientific Nutating Mixers, model 05450-213). Next, saliva supernatant was removed, and the beads were washed three times with $A B$ buffer containing PMSF and $\mathrm{NaN}_{3}$. The sHA beads were now ready for downstream assays.

\section{Effect of treatments on the initial glucan matrix formation}

Samples of sHA were obtained as described above. Next, $500 \mu \mathrm{L}$ of GtfB enzyme were added to each tube followed by incubation in a homogenizer $\left(40 \mathrm{~min}, 37^{\circ} \mathrm{C}\right.$, $24 \mathrm{rpm}$; Fisher Scientific Nutating Mixers) and washing three times with $\mathrm{AB}$ buffer (containing PMSF and $\left.\mathrm{NaN}_{3}\right)$. After, $500 \mu \mathrm{L}$ of selected extracts $(0.50 \mathrm{mg} / \mathrm{mL})$ that showed antibiofilm activity against $S$. mutans (or controls) were added to each tube, followed by incubation in a homogenizer $\left(30 \mathrm{~min}, 37^{\circ} \mathrm{C}, 24 \mathrm{rpm}\right.$; Fisher Scientific Nutating Mixers) and washing three times with $\mathrm{AB}$ buffer (containing PMSF and $\mathrm{NaN}_{3}$ ). Then, $500 \mu \mathrm{L}$ of sucrose substrate ( $100 \mathrm{mmol}$ of sucrose) were added to each tube and incubated in a homogenizer $\left(4 \mathrm{~h}, 37^{\circ} \mathrm{C}\right.$, $24 \mathrm{rpm}$; Fisher Scientific Nutating Mixers). To stop the synthesis of glucans and to precipitate the formed glucans, $500 \mu \mathrm{L}$ of $99 \% \mathrm{EtOH}$ was added, followed by incubation $\left(18 \mathrm{~h},-20^{\circ} \mathrm{C}\right)$. After that, the pellets were washed three times with $70 \% \mathrm{EtOH}$ to remove excess sucrose not incorporated into the synthesized glucans and dried (Speed Vac Concentrator RVC 2-18 CD Plus, Christ). For solubilization of the glucans produced, $200 \mu \mathrm{L}$ of 1 $\mathrm{N} \mathrm{NaOH}$ were added to each sample, followed by incubation $\left(2 \mathrm{~h}, 37^{\circ} \mathrm{C}, 300 \mathrm{rpm}\right.$; Fisher Scientific Dry-BathIncubator, model 980FIHSCTSUs) and centrifugation. Afterward, the $200 \mu \mathrm{L}$ supernatant was transferred to a 
new tube per sample, and another aliquot of $200 \mu \mathrm{L}$ of 1 $\mathrm{N} \mathrm{NaOH}$ was added to the tubes containing the treated beads and re-incubated $\left(2 \mathrm{~h}, 37^{\circ} \mathrm{C}, 300 \mathrm{rpm}\right.$; Fisher Scientific Dry-Bath-Incubator). Then, the $200 \mu \mathrm{L}$ supernatant was transferred to the corresponding tubes to obtain a final volume of $400 \mu \mathrm{L}$. The resulting supernatants were used for the quantification of water insoluble glucans via phenol and sulfuric acid colorimetric assay with glucose as standard [42].

\section{The detachment of S. mutans after adhesion to salivary pellicle and glucans treated with selected extracts}

The microorganisms were grown to the mid-log growth phase as described above. When cultures reached the desired OD, they were centrifuged $(4000 \times g$ for $20 \mathrm{~min}$ ), washed with $0.89 \% \mathrm{NaCl}$ solution, and resuspended in the same initial volume. Cultures were sonicated with a probe to dechain ( $30 \mathrm{~s}, 7$ watts, 3 times; QSonica, model 125 , Newtown, USA). OD $_{540 \mathrm{~nm}}$ was checked to adjust the concentration to $2 \mathrm{E}+06 \mathrm{CFU} / \mathrm{mL}$.

\section{Adhesion of S. mutans to the salivary pellicle followed by the detachment of adhered cells}

Samples of sHA were obtained as described above. After that, $500 \mu \mathrm{L}$ of selected extracts $(0.50 \mathrm{mg} / \mathrm{mL})$ that showed antibiofilm activity against $S$. mutans (or controls) were added to each tube, followed by incubation in a homogenizer $\left(30 \mathrm{~min}, 37^{\circ} \mathrm{C}, 24 \mathrm{rpm}\right.$; Fisher Scientific Nutating Mixers) and washing three times with $A B$ buffer (containing PMSF and $\mathrm{NaN}_{3}$ ). Then, $500 \mu \mathrm{L}$ of $S$. mutans culture $(2 \mathrm{E}+06 \mathrm{CFU} / \mathrm{mL})$ were added to each tube, followed by incubation $\left(1 \mathrm{~h}, 37^{\circ} \mathrm{C}, 24 \mathrm{rpm}\right)$ and washing three times with $\mathrm{AB}$ buffer (containing PMSF and $\mathrm{NaN}_{3}$ ) to remove unbound cells. Each sample was resuspended with $1000 \mu \mathrm{L}$ of $\mathrm{AB}$ buffer and sonicated with a probe to detach cells adhered to sHA (30s, 7 watts). An aliquot of each suspension was used for a 10fold serial dilution $\left(10^{0}\right.$ to $\left.10^{-3}\right)$ to determine the number of viable colonies by plating on blood agar plates $\left(48 \mathrm{~h}, 37^{\circ} \mathrm{C}, 5 \% \mathrm{CO}_{2}\right)$. This evalulation verifies whether the extracts used are capable of inhibiting the adherence of $S$. mutans to the salivary pellicle, but mainly, whether the cells of the microorganism that have adhered to the treated pellicle can be removed from the surface more easily by the mechanical stimulus, thus interrupting the first stage of biofilm formation.

\section{Adhesion of S. mutans to the initial glucan matrix (gsHA) followed by the detachment of adhered cells}

Samples of sHA were obtained as described above. Then, $500 \mu \mathrm{L}$ of GtfB enzyme were added to each tube, followed by incubation in a homogenizer $\left(40 \mathrm{~min}, 37^{\circ} \mathrm{C}\right.$, $24 \mathrm{rpm}$; Fisher Scientific Nutating Mixers) and washing three times with $\mathrm{AB}$ buffer (containing PMSF and
$\mathrm{NaN}_{3}$ ). Afterward, $500 \mu \mathrm{L}$ of sucrose substrate (100 mmol of sucrose) containing the treatments (or controls-at the concentration $0,5 \mathrm{mg} / \mathrm{mL}$ ) were added to each tube. The samples were then incubated in a homogenizer $\left(4 \mathrm{~h}, 37^{\circ} \mathrm{C}\right.$, $24 \mathrm{rpm}$; Fisher Scientific Nutating Mixers). After the incubation, three washes were performed with $\mathrm{AB}$ buffer (with PMSF and $\mathrm{NaN}_{3}$ ) to remove the treatments and excess of sucrose not incorporated in the synthesized glucans (samples of gsHA). Subsequently, $500 \mu \mathrm{L}$ of $S$. mutans inoculum $(2 \mathrm{E}+06$ $\mathrm{CFU} / \mathrm{mL}$ ) were added to each tube followed by incubation in a homogenizer $\left(1 \mathrm{~h}, 37^{\circ} \mathrm{C}, 24 \mathrm{rpm}\right.$; Fisher Scientific Nutating Mixers) and washing three times with $A B$ buffer (with PMSF and $\mathrm{NaN}_{3}$ ) to remove unbound cells. Each sample was resuspended with $1000 \mu \mathrm{L}$ of AB buffer (with PMSF and $\mathrm{NaN}_{3}$ ) and sonicated with probe to detach cells adhered to gsHA (30 s, 7 watts). An aliquot of each suspension was used for a 10 -fold serial dilution $\left(10^{0}\right.$ to $\left.10^{-3}\right)$ to determine the number of CFU by plating on blood agar plates $\left(48 \mathrm{~h}, 37^{\circ} \mathrm{C}, 5 \% \mathrm{CO}_{2}\right)$. This evalulation verifies whether the extracts used are able to inhibit the adhesion of $S$. mutans to the initial glucan matrix, but mainly, if the cells of the microorganism that have adhered to the treated glucans can be removed by the mechanical stimulus more easily of the surface, thus interrupting the stage biofilm formation.

\section{Cytotoxicity of selected extracts}

For cytotoxicity assays, the concentration of $0.5 \mathrm{mg} / \mathrm{mL}$ of each selected extract (PAC/CE, FLO/SC, PRE/SP, GUA/CE, MOG/SP, SRM/MG, and ARA/SP) was used.

\section{Cell culture}

Keratinocytes NOK-si lineage [43] cells were grown in Dulbecco's Modified Eagle's Medium (DMEM, GIBCO, Grand Island, NY, USA) with $2 \mathrm{mM}$ glutamine; containing $10 \%$ fetal bovine serum (FBS, GIBCO, Grand Island, $\mathrm{NY})$, penicillin G $(10,000 \mu \mathrm{g} / \mathrm{mL})$, streptomycin (10, $000 \mu \mathrm{g} / \mathrm{mL})$ and amphotericin $(25 \mu \mathrm{g} / \mathrm{mL})$ (Invitrogen). The culture was incubated at $37^{\circ} \mathrm{C}$ and an atmosphere of $5 \% \mathrm{CO}_{2}$. The cells were grown to confluency (90\%), washed with 1X PBS phosphate buffer $(140 \mathrm{mM} \mathrm{NaCl}$, $\left.3.0 \mathrm{mM} \mathrm{KCl}, 4.30 \mathrm{mM} \mathrm{Na}_{2} \mathrm{HPO}_{4}, 1.40 \mathrm{mM} \mathrm{KH_{2 }} \mathrm{PO}_{4}\right)$, removed with trypsin $(0.05 \%) /$ EDTA solution $(0.53 \mathrm{mM})$ (Invitrogen), and then centrifuged at $400 \times \mathrm{g}$ for $5 \mathrm{~min}$. The cells were resuspended in the same culture medium and replated. The medium was changed every two or 3 days. For the experiments, cells between the 3rd and 8th passage were used. Cells were counted in Neubauer's chamber and plated in 96-well microplate wells $(2.0 \mathrm{E}+$ 04 cells per well). The plates were incubated for $24 \mathrm{~h}$ $\left(5 \% \mathrm{CO}_{2} ; 37^{\circ} \mathrm{C}\right)$. 


\section{Cell viability assay - MTT}

Cytotoxicity resulting from the presence of treatments $(0.50 \mathrm{mg} / \mathrm{mL}$ of extracts, vehicle control, and death control- $0.11 \%$ Triton X-100) and untreated control (cell viability control) on monolayer cells was determined by the colorimetric assay of cell viability MTT [3- $(4,5-$ dimethylthiazol-2-yl) 2, 5-diphenyltetrazolium bromide] (Sigma) $[44,45]$.

This assay was performed using cell culture in monolayer, $1 \mathrm{~h}$ after contact with extracts and controls included in the culture medium. After the incubation period, the cells were washed with $500 \mu \mathrm{L}$ of PBS (pH 7.4) and incubated $\left(4 \mathrm{~h} ; 37^{\circ} \mathrm{C} ; 5 \% \mathrm{CO}_{2}\right)$ with $250 \mu \mathrm{L}$ of MTT solution $(5.0 \mathrm{mg} / \mathrm{mL})$. Then the forming crystals were solubilized in $250 \mu \mathrm{L}$ of 2-propanol added to each well. Spectrophotometric measurements were performed at a wavelength of $562 \mathrm{~nm}$. Two experimental occasions were performed with 4 replicates per occasion $(n=8)$. The data obtained were converted into a percentage of viable cells and compared to the control without treatment (control of cell viability). The ISO 10993-5:2009 guideline was used to determine the cytotoxicity level [46].

\section{Statistical analyses}

Statistical analyses were performed using GraphPad Prism7 software (GraphPad Software, Inc., La Jolla, CA, USA), with a $5 \%$ significance level. The Shapiro-Wilk normality test was used. Most data presented a nonnormal distribution and were evaluated by the KruskalWallis non-parametric test, followed by Dunn's multiple comparison test. Only the fractions results presented normal distribution and were assessed by two-way ANOVA considering the factors biome and fractions, followed by Tukey's multiple comparisons test.

\section{Results}

\section{Characteristics of $C$. sylvestris extracts from distinct Brazilian biomes}

In an earlier study, an analytical method was developed using liquid chromatography and chemometrics to evaluate and differentiate two varieties of C. sylvestris Swartz (Salicaceae) from the State of São Paulo (Brazil) based on secondary metabolite profiles [33]. Previously, the analytical studies related only to the analysis of clerodane-type diterpenes. Afterward, this method was also applied to describe the flavonoid composition of $C$. sylvestris varieties [47] and the analysis of the composition of leaves extracts of other Brazilian states. Thus, considering the importance of the inclusion of phenolic compounds in analyses, a strategy was employed to simultaneously extract and detect the largest number of compounds of both chemical classes. Two peaks were selected from the resulting chromatograms and included both phenolic compounds (more precisely, glycosylated flavonoids, detected at $254 \mathrm{~nm}$ ) and clerodane-type diterpenes (detected at $235 \mathrm{~nm}$ ) [33]. This new strategy allowed an exhaustive chromatographic analysis of $C$. sylvestris and the results showed that the varieties presented an interesting distribution according to their original ecosystems, suggesting a strong correlation with the main metabolites found in each group of species. In addition to the inherent morphological differences, it was also possible to observe differences in the composition of the secondary metabolite within each group, depending on the place where the samples were collected [33].

Here, extracts from C. sylvestris var. sylvestris (PAC/ $\mathrm{CE}, \mathrm{FLO} / \mathrm{SC}, \mathrm{PRE} / \mathrm{SP}$, and GUA/CE) presented higher content of clerodane-type diterpenes and lower content of glycosylated flavonoids. However, the extracts of intermediate morphology (CAM/SP, MOG/SP, RIO/RS, and $\mathrm{CAC} / \mathrm{MT}$ ) present higher content of glycosylated flavonoids and lower content of clerodane-type diterpenes, while extracts from var. lingua (CAR/CE, LUI/SP, SRM/MG, and ARA/SP) present the highest content of glycosylated flavonoids (Fig. 1). Thus, not only the biome but the morphology interfered with the composition of tested extracts.

\section{Antimicrobial activity}

The CFU/mL data were converted to $\log _{10}$ percentages to evaluate which extracts at the concentration tested inhibited $\geq 50 \%$ of the viable counts of microbial population per tested strains $\left(\mathrm{IC}_{50}\right.$ or $\geq 3 \operatorname{logs}$ ) [48]. Significant reductions in the microbial population of $S$. mutans were seen when treated by FLO/SC (53.84\% reduction), GUA/CE (65.91\% reduction) and PRE/SP (48.93\%) compared with the control vehicle $(p<0.0001$, Fig. $2 \mathrm{a})$. There was also a significant reduction in the microbial population of $C$. albicans when treated with PAC/CE (50.3\% reduction), and PRE/SP (52.98\% reduction) ( $p=0.0001$ vs. vehicle; Fig. $2 \mathrm{~b}$ ); these extracts belong to var. sylvestris and contemplate the Atlantic Forest biome.

The antimicrobial activity against $S$. mutans was also evaluated for the 36 fractions of the extracts, being $\mathrm{MeOH}, \mathrm{AcOEt}$, and Hex fractions. The AcOEt fractions of all extracts reduced the microbial population of $S$. mutans $(p<0.0001$ vs. vehicle), except PAC/CE $(p>$ 0.05 vs. vehicle). The AcOEt fractions ARA/SP, CAR/ $\mathrm{CE}$, and SRM/MG caused a greater reduction in the viability of the $S$. mutans population (82.91, 92.76, and $100 \%$, respectively) compared to the other AcOEt fractions (Fig. 3). The extracts to which these fractions belong are var. lingua and Cerrado and Ecotone (Cerrado/ Caatinga) biomes and express a high content of glycosylated flavonoids. However, AcOEt is a solvent with optimum polarity to extract the diterpenes, especially 


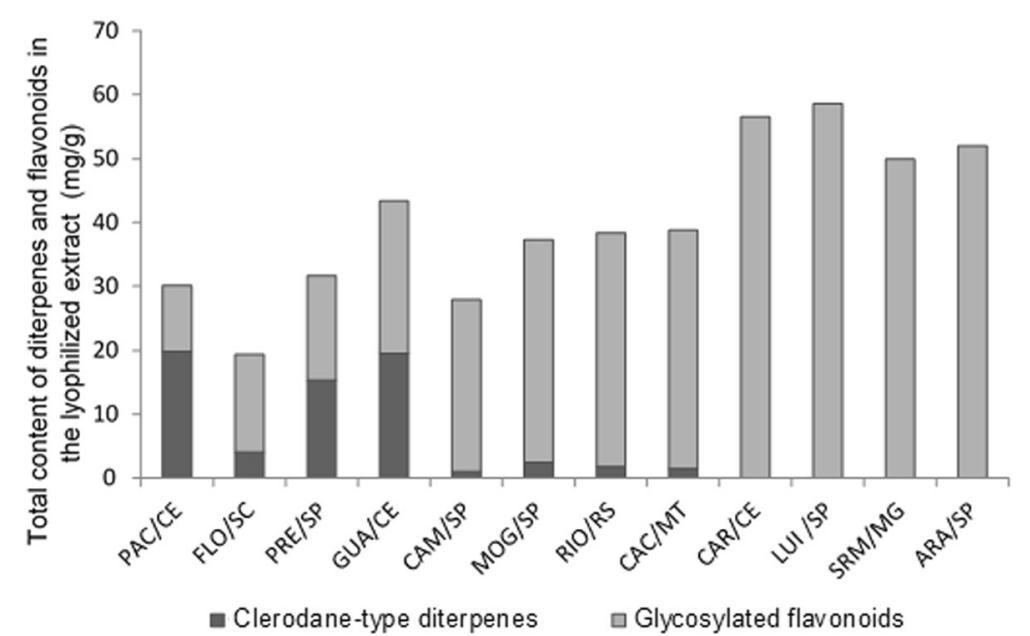

Fig. 1 Quantity of clerodane-type diterpenes and glycosylated flavonoids in C. sylvestris extracts from Brazilian biomes. The letters $S$, I and $L$ indicate the varieties sylvestris, intermediate and lingua, respectively. (Personal communication by Dr. Paula Carolina Pires Bueno)

the casearins, while the flavonoids are retained in the extraction cartridge. Thus, the resulting fraction has a higher content of diterpenes of the type clerodane compared to glycosylated flavonoids (Bueno PCP, unpublished observation).

\section{Antibiofilm activity}

Biofilm data were converted into percentages and extracts that reduced biofilm biomass and/or counts of viable microorganisms averaged more than 50\% were considered promising for testing against specific virulence mechanisms. When compared to vehicle control, the highest biomass reduction of $S$. mutans was observed in biofilms treated with the extracts GUA/CE (95.87\%), PAC/CE (91\%), and PRE/SP (99.76\%) ( $p<0.0001$; Fig. 4a). In addition, significant reductions in the viable count of the bacterial population were observed for ARA/SP, CAM/SP, FLO/SC, GUA/CE, MOG/SP, PAC/CE, PRE/ SP, and SRM/MG ( $p<0.0001$ vs. V; Fig. 4c). Biofilms treated with GUA/CE, PAC/CE, PRE/SP, and SRM showed a $100 \%$ median reduction in S. mutans viable counts (Fig. 4c).

The biofilms of $C$. albicans treated with $\mathrm{PAC} / \mathrm{CE}$, $\mathrm{PRE} / \mathrm{SP}, \mathrm{RIO} / \mathrm{RS}$, and SRM/MG showed a reduction of the viable counts of the fungus $(p<0.0095$ vs. vehicle; Fig. 4d), but for RIO/RS and SRM/MG there was high variability of the obtained data. The biomass data also presented high variability, and no differences between treatments with extracts and vehicle control were identified (Fig. 4b).

\section{Effect of selected extracts on GtfB activity}

The effect of extracts on GtfB activity of $S$. mutans was evaluated for treatments with $\mathrm{FLO} / \mathrm{SC}, \mathrm{GUA} / \mathrm{CE}, \mathrm{PAC} /$ $\mathrm{CE}$, and PRE/SP extracts, as these extracts presented better results for antimicrobial and antibiofilm analyses. Data from 3 experiments in triplicate, with three replicate readings are shown in Fig. 5. The FLO/SC, GUA/ $\mathrm{CE}$, and PRE/CE extracts reduced the amount of glucans formed by GtfB ( $p \leq 0.0136$ vs. V), however, PAC/CE did not affect the amount of glucans $(p=0.6032)$.

The detachment of $S$. mutans after adhesion to salivary pellicle and to the initial matrix of glucans treated with selected extracts

The quantification of $S$. mutans cells that were detached by mechanical stimulation after adhesion to the salivary pellicle and glucans was evaluated for treatments with the extracts FLO/SC, GUA/CE, PAC/CE, and PRE/SP, as these four extracts presented better results for antimicrobial and antibiofilm evaluations. No extract interfered with the removal of cells adhered to the treated pellicle ( $p>0.05$ vs. vehicle; Fig. $6 \mathrm{a})$; thus, these extracts may not modify the pellicle per se. However, a greater number of $S$. mutans cells were detached after adhesion to the treated glucan matrix $(p<0.0031$ vs. vehicle; Fig. 6b).

\section{Cytotoxicity of selected extracts}

The cell viability data (NOK-si lineage) showed that exposure of these cells for $1 \mathrm{~h}$ to the tested extracts and the vehicle-control caused cell death, as compared to the viability control (Fig. 7). The ISO 10993-5:2009 provides guideline for the cytotoxicity classification as not cytotoxic, when there is inhibition of cell viability of less than $25 \%$ compared to the control group (cell viability control-"Cont L"); slightly cytotoxic, with inhibition between 25 and $50 \%$ in comparison with the control group ("Cont L"); moderately cytotoxic, with inhibition between 50 and $75 \%$ in comparison with the control group 


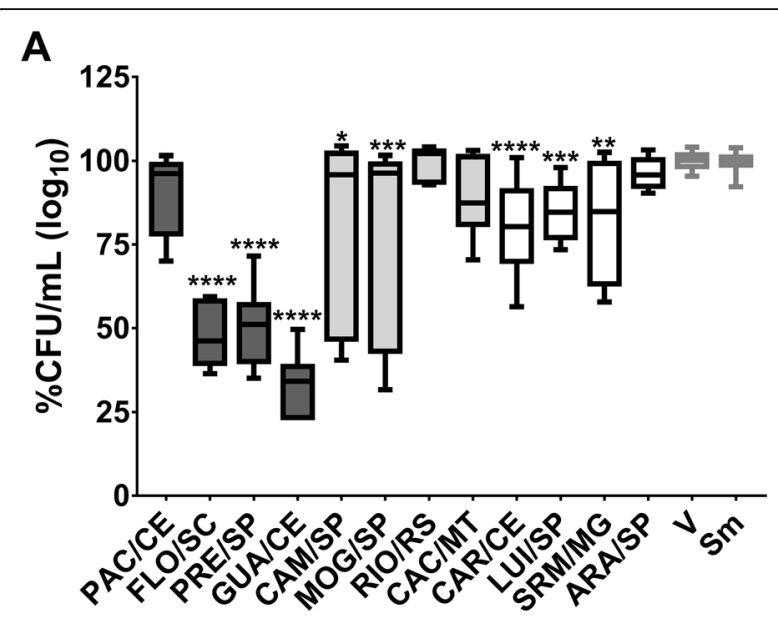

B

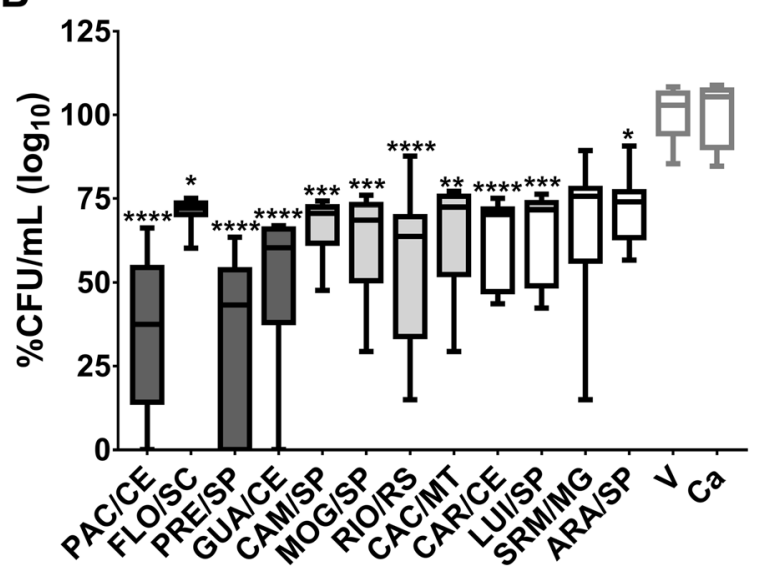

Fig. 2 Antimicrobial activity of C. sylvestris extracts from Brazilian biomes against $S$. mutans and $C$. albicans. a shows $S$. mutans data while (b) depicts C. albicans data. The data are median (traces) and interquartis (boxes) for the 12 extracts evaluated. The error bars represent the maximum and minimum values. Asterisks denote statistically significant difference of a specific extract versus vehicle (V) control, where: ${ }^{* * *} p \leq 0.0001 ;{ }^{* *} p \leq 0.001 ;{ }^{* *} \leq p<0.01$; and ${ }^{*} p \leq 0.05$ (Kruskal-Wallis test, followed by Dunn's multiple

comparisons test). Each species growth control (without treatment) is represented as Sm for S. mutans and Ca for C. albicans. The colors of the bars in each graph represent the variety to which the extracts belong, being, in dark gray color: var. sylvestris; light gray: var. intermediate and white: var. lingua

("Cont L"); and strongly cytotoxic, with inhibition higher than $75 \%$ of that of the control group ("Cont L") [46]. Therefore, the treatments promoted slight cytotoxicity (PRE/SP, GUA/CE, MOG/SP, SRM/MG, ARA/SP, and $\mathrm{V}$ control) and moderate cytotoxicity (PAC/CE and FLO/SC). However, there was no difference between extracts and vehicle control $(p>0.9999)$.

\section{Discussion}

The results obtained in this study indicate that certain extracts and fractions of C. sylvestris exhibit potent antimicrobial and antibiofilm effects against two of the main microorganisms related to the pathogenesis of dental caries. Previous studies that performed systematic screenings of $C$. sylvestris demonstrated a varied phytochemical composition for leaf extracts [32, 33]. This varied phytochemical composition (presence of clerodan diterpenes and glycosylated flavonoids) provides a rich source of molecules that may exhibit cariostatic properties, and their potential must be explored. Also, the natural origin of these extracts allows them to be more easily accepted for the long-term control of biofilmmediated diseases, such as dental caries, in addition to being less costly [49].

Here, the tested samples of $C$. sylvestris extracts and fractions were from three distinct varieties (lingua, intermediate, and sylvestris) that cover the five Brazilian biomes. The relevance of screening samples of different varieties and biomes is due to the variability of chemical composition concerning secondary metabolites. The chemical composition of $C$. sylvestris is related and/or conditioned by the biomes, and mainly associated with the respective predominant morphotypes and, therefore, under strong genetic control. The different origin biomes influence the production of secondary metabolites in the C. sylvestris varieties and, therefore, also associated with the respective predominant morphotypes. There was evidence of the differential production of flavonoids and clerodanic diterpenes by the var. lingua and sylvestris, respectively, which was constant throughout the circadian cycle and had modulations only in the reproductive period (Bueno PCP, unpublished observation). This variability should, therefore, be considered for the biological activity of natural products derived from C. sylvestris.

Although Minimum Inhibitory Concentration (MIC) and Minimum Bactericidal and Fungicidal Concentration $(\mathrm{MBC} / \mathrm{MFC})$ tests are widely used to determine the activity of new compounds [37, 48,50], the number of extracts and fractions evaluated here has limited the use of that methodology. Therefore, based on concentrations reported in the literature [34, 35], an antimicrobial activity screening was performed using a single concentration of each extract. This screening model allowed a larger number of samples to be evaluated in a single experiment and identified extracts/fractions with potential inhibitory effects. Nevertheless, the antimicrobial assay data obtained showed that the concentration of $0.50 \mathrm{mg} /$ $\mathrm{mL}$ of specific extracts inhibited $\geq 50 \%$ of the viable counts of the microbial population for both the bacteria and the fungus $\left(\mathrm{IC}_{50}\right.$ or $\left.\geq 3 \operatorname{logs}\right)$ [48]. For $S$. mutans, the extracts that inhibit $\geq 3$ logs were FLO/SC, GUA/CE, and PRE/SP; while both PAC/CE and PRE/SP reduced $\geq$ $3 \operatorname{logs}$ of $C$. albicans population. Therefore, the four extracts $\mathrm{FLO} / \mathrm{SC}$, GUA/CE, PAC/CE, and PRE/SP could be used to obtain the MIC and $\mathrm{MBC}$ data in a future study. 


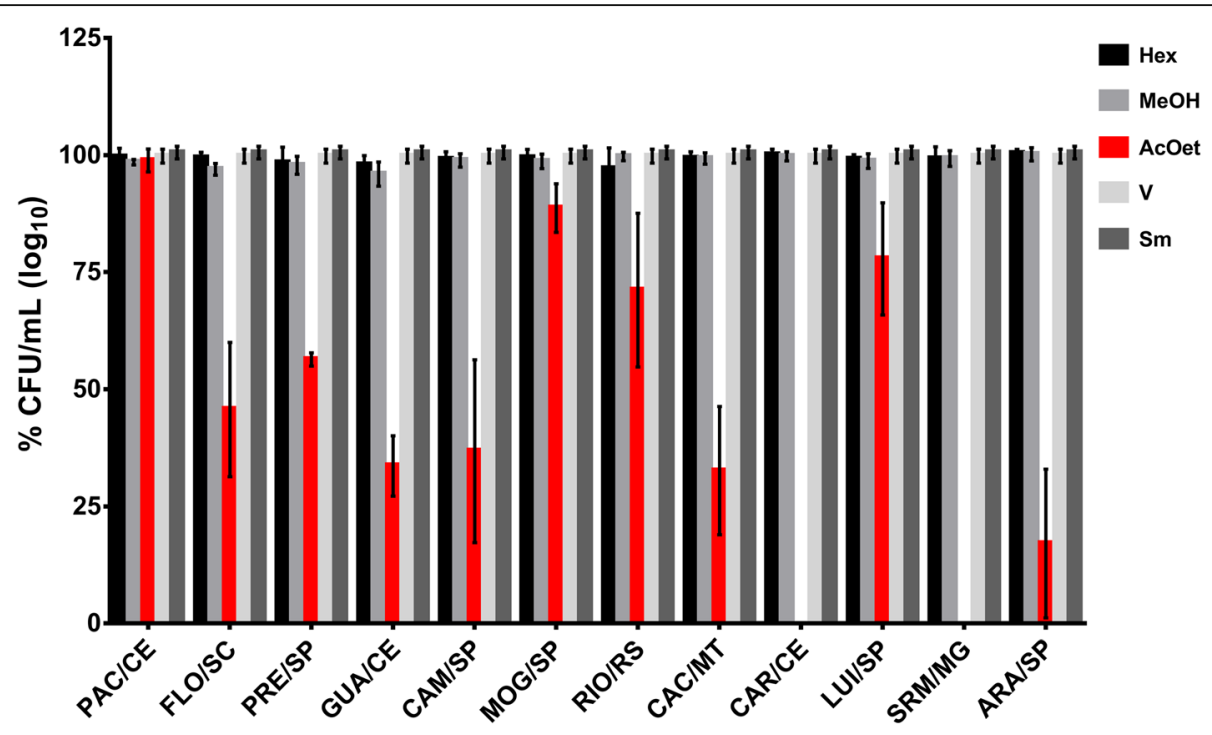

Fig. 3 Antimicrobial activity of three distinct fractions C. sylvestris from distinct Brazilian biomes against S. mutans. Data depicted are average and standard deviation. There was statistically significant difference between fraction AcOEt versus vehicle $(V)$ control for all, except PAC/CE $(p \leq$ 0.0001; two-way ANOVA between the bioma and fraction factors showed that the interaction between the factors is significant by factor $p<$ 0.0001 ; biome $p<0.0001$ and fraction $p<0.0001$, followed by the Tukey multiple comparisons test; $p>0.050$ )

A

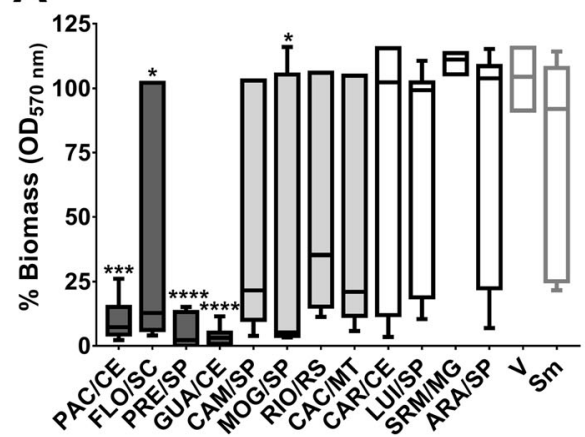

C

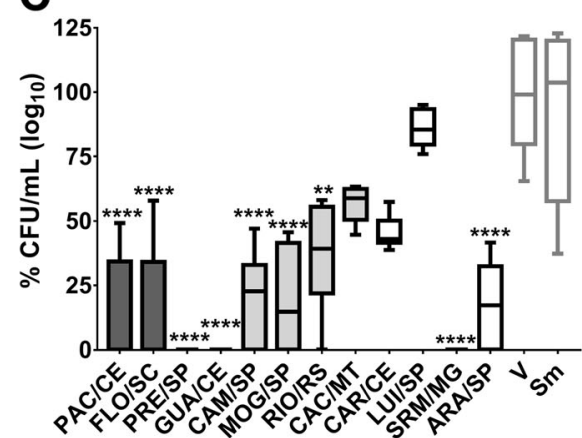

B

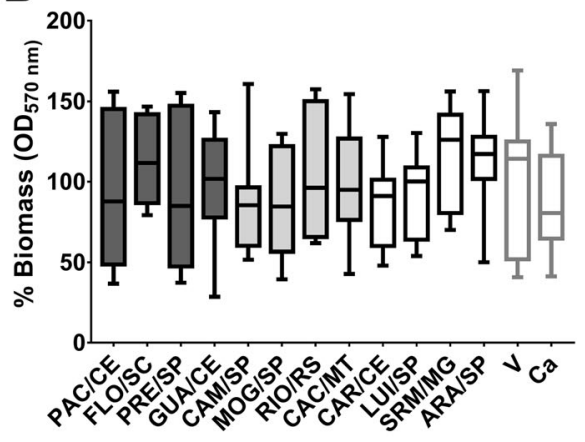

D

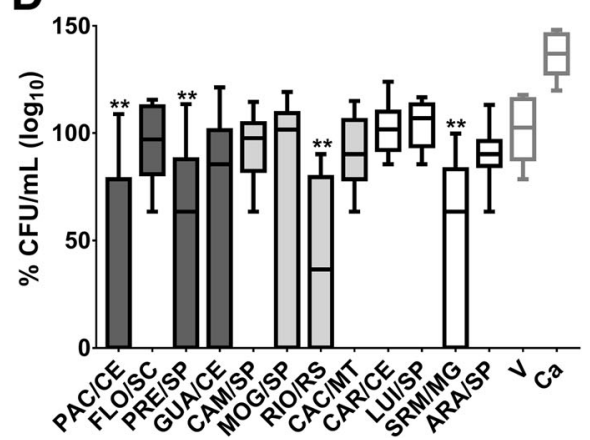

Fig. 4 Antibiofilm activity of C. sylvestris extracts from Brazilian biomes against S. mutans and C. albicans. The biomass data obtained via violet crystal method are shown in (a) and (b) for S. mutans and C. albicans, respectively. The microbial viable counts data are shown in (c) and (d) for S. mutans and C. albicans, respectively. Note that the extracts presented more effect against S. mutans biofilms than against $\mathrm{C}$. albicans ones. The data described are median (traces) and interquartis (boxes) of the 12 tested extracts. The error bars represent the maximum and minimum values.Asterisks denote statistically significant difference of a specific extract versus vehicle $(\mathrm{V})$ control, where: ${ }^{* * *} p \leq 0.0001 ;{ }^{* * *} p \leq 0.001 ;{ }^{* *} \leq$ $p<0.01$; and ${ }^{*} p \leq 0.05$ (Kruskal-Wallis test, followed by Dunn's multiple comparisons test). Each species growth control is represented as Sm for S. mutans and Ca for C. albicans. The colors of the bars of the graph represent the variety to which the extracts belong, being, in dark gray color: var. sylvestris; light gray: var. intermediate and white: var. lingua 


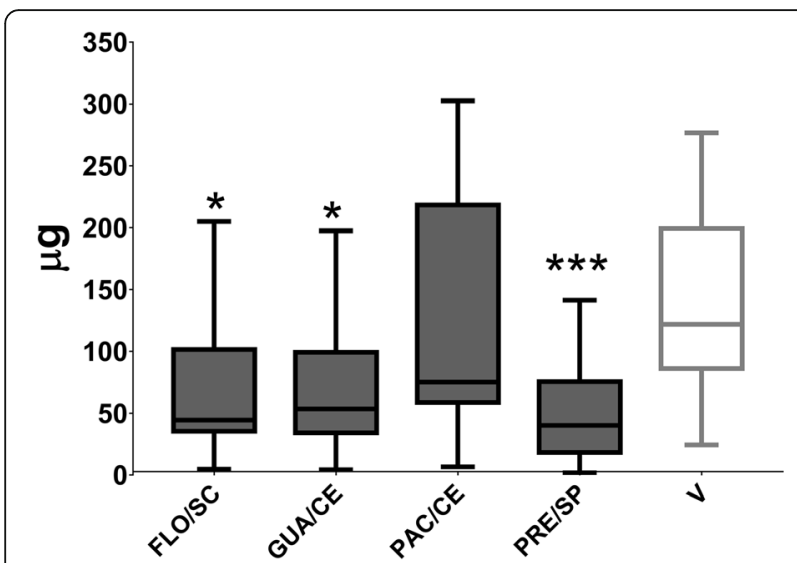

Fig. 5 Effect of FLO/SC, GUA/CE, PAC/CE, and PRE/SP extracts on GtfB activity. The data described are median (traces) and interquartis (boxes). The error bars represent the maximum and minimum values. Asterisks indicate statistically significant differences from a specific extract versus vehicle control $(V)$, where: ${ }^{* *} p<0.0136$ and *** $p=0.0002$ (Kruskal-Wallis test, followed by Dunn's multiple comparison test). Only the PAC / CE extract did not affect GtfB activity $(p=0.6032)$. The colors of the bars of the graph represent the variety to which the extracts belong, being, in dark gray color: var. sylvestris

Similarly, among the 12 AcOEt fractions at $0.25 \mathrm{mg} / \mathrm{mL}$, seven decreased $\geq 3 \operatorname{logs}$ of $S$. mutans (FLO/SC, GUA/ CE, CAM/SP, CAC/MT, CAR/CE, SRM/MG, and ARA/ SP), and could also be used for MIC evaluation in the future. Thus, the current findings will direct studies for optimization of extract/fraction concentration (or extract/fraction combination) in more complex in vitro (e.g., microcosm) and in vivo models.

The single-species biofilm model used in this study has been recommended for initial screenings of new anti-caries agents [51] and, although it does not mimic the complexity of the microbiota of the teeth' coronal surfaces, expresses a critical virulence characteristic of the biofilm, the polysaccharide matrix [52]. The advantages of this model include high reproducibility of biofilm formation; allows high throughput screening of multiple compounds and concentrations in a single experiment $[38,53]$; the treatment steps can be consistently controlled $[54,55]$.

In addition, biofilms using a single microorganism are advantageous for the analysis of the mechanisms of action of therapeutic agents, especially in the glucanmediated processes involved in the formation of the polysaccharide matrix in the $S$. mutans biofilm [52]. Single-species model is also resourceful for the formation of hyphae, a critical virulence factor of C. albicans. This fungus has also been chosen for the initial screening of extracts as it is one of the microorganisms frequently detected in biofilms (dental plaque) of children affected by early childhood caries [56] and provides an

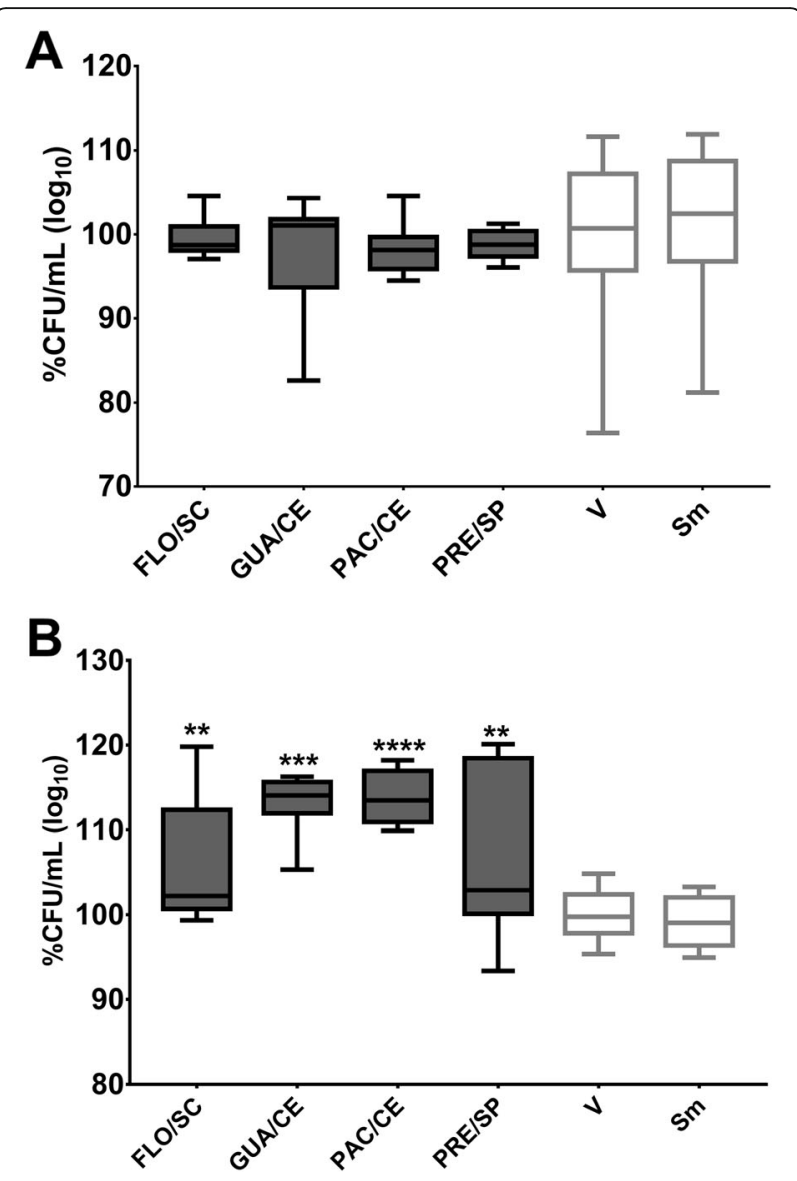

Fig. 6 S. mutans detachment after adhesion to the treated salivary pellicle and initial matrix of glucans. Post-release data of $S$. mutans to the treated salivary pellicle and glucans are shown in (a) and (b), respectively. There was no difference between the control vehicle $(V)$, and the extracts tested for both analyses. The percentage of $\mathrm{CFU} / \mathrm{mL}$ was obtained considering the vehicle control (V) as 100\%. The data described are median (traces) and interquartis (boxes). The error bars represent the maximum and minimum values. The asterisks denote a statistically significant difference of a specific extract versus vehicle control $(V)$, where ${ }^{* * *} p=0.0001$ and ${ }^{* *} p<$ 0.0031 (Kruskal-Wallis test, followed by the multiple comparison test of Dunn). The growth control is represented by Sm for S. mutans. The colors of the bars of the graph represent the variety to which the extracts belong, being the color dark gray to var. sylvestris

increase in the binding sites of $S$. mutans derived Gtfs [57]. The results of antimicrobial and antibiofilm tests (biomass and viable population data) indicate that $\mathrm{FLO} /$ SC, GUA/CE, PAC/CE, and PRE/SP made the most significant reductions for $S$. mutans. These four extracts are from the Atlantic Forest, var. sylvestris.

Among these extracts, PAC/CE and PRE/CE presented a concomitant reduction of $C$. albicans viable counts in both antimicrobial and antibiofilm evaluations. These findings can be attributed to the extracts' phytochemical composition, which is marked by the simultaneous presence of phenolic compounds (glycosylated flavonoids) 


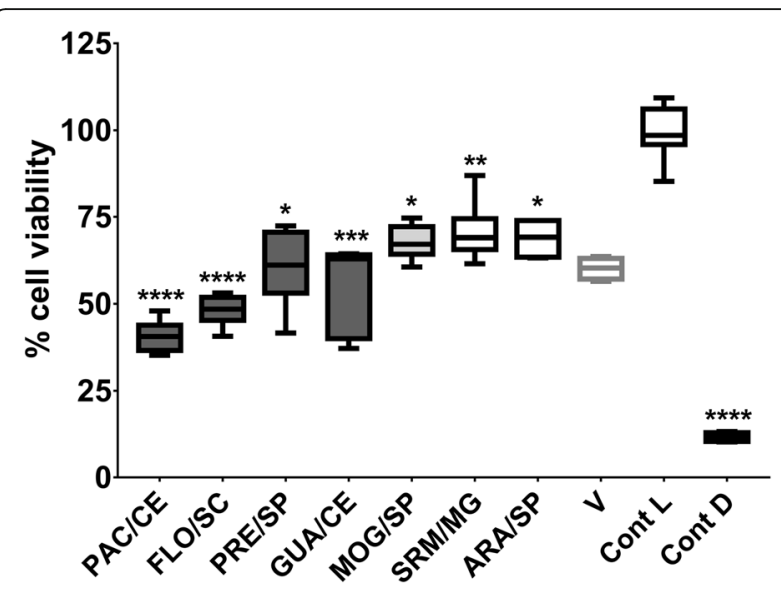

Fig. 7 Cell viability of keratinocytes NOK-si after exposure to selected extracts. The data described are the medians and the interquartile ranges. The data described are median (traces) and interquartis (boxes). The error bars represent the maximum and minimum values. "Cont L" indicates cell viability control and "Cont $\mathrm{D}^{\prime \prime}$, the cell death control. The percentage of cell viability was obtained considering the cell viability control as 100\%. The asterisks denote a statistically significant difference of a specific extract versus cell viability control control (Cont $\mathrm{L}$ ), where ${ }^{* * *} p<0.0001,{ }^{* * *} p=$ $0.0004,{ }^{* *} p=0.0088$, and ${ }^{*} p \leq 0.0204$ (Kruskal-Wallis test, followed by the multiple comparison test of Dunn). The colors of the bars of the graph represent the variety of the extracts, being, in dark gray: var. sylvestris; in light gray: var. intermediate; and blank: var. lingua

and clerodane-type diterpenes. The presence of both plant metabolites in these extracts can be particularly advantageous over the other extracts because flavonoids and terpenoids belong to the classes of compounds reported to be effective for controlling virulence factors of cariogenic microorganisms [58]. Thus, the best biological activity observed for the four extracts (FLO/SC, GUA/CE, PAC/CE, and PRE/SP) can be attributed to a potential synergism between the plant metabolites, which promotes multi-target effects. This hypothesis is because the other extracts evaluated present in their composition the predominance of only one of the metabolite classes, and none of them produced significant inhibitory effects.

The current study aimed not to isolate bioactive compounds from extracts and fractions and to identify their possible targets of action, but to perform a systematic screening to identify which ones have a potential biological activity to control/prevent cariogenic biofilm. However, knowledge of the secondary metabolites found in C. sylvestris leaf extracts provided the basis for the interpretation of the results found. C. sylvestris has secondary metabolites that confer different pharmacological properties to the plant and justify its use in folk medicine. A previous phytochemical study provided valuable information about the phenolic components from the leaves of the ARA/SP extract, following the same extraction method as the extracts tested here [33, 47]. Fourteen glycosylated flavonoids and one catechin were isolated and identified, as follows: $(+)$-catechin, quercetin-3-O- $\alpha$-L-rhamnopyranosyl- $(1 \rightarrow 6)-\beta-D$ glucopyranoside (rutin), isorhamnetin-3-O- $\alpha$-L-rhamnopyranosyl-( $1 \rightarrow 2)$ - $ß$-Dglucopyranoside (isorhamnetin-3-Oneo-hesperidoside, isorhamnetin-3-O- $\alpha$-Lrhamnopyranosyl-( $1 \rightarrow 6)-\beta \quad$-D-glucopyranoside (narcissin) e isorhamnetin-3-O- $\alpha$-Lrhamnopyranosyl- $(1 \rightarrow 2)-\alpha \quad$-Larabinopyranoside [47]. A previous study [33] with ARA/SP, CAM/SP, MOG/SP, and PRE/SP samples selected two peaks from the chromatograms and included the clerodane-type diterpenes (casearins) detected at $235 \mathrm{~nm}$. Other chemical investigations have isolated 41 clerodane-type diterpenes, including casearins [59-64] and casearvestrins [65].

Flavonoids have different pharmacological properties, including antimicrobial and antioxidant activities [66, 67]. These compounds may be complexed with extracellular and soluble proteins as well as with bacterial cell wall and can also inhibit Gtfs activity [66, 67]. In contrast, terpenoids can promote rupture of the microbial cell membrane by their lipophilic characteristics [68]. Therefore, the activity of these compounds may justify the antimicrobial activity against $S$. mutans ( $\geq 50 \%$ reduction of viable bacterial counts) caused by Atlantic Forest extracts, var. sylvetris. Further investigation is needed to corroborate these effects of $C$. sylvestris.

The S. mutans viable counts data after treatment with ARA/SP, CAR/CE, and SRM/MG ethyl acetate fractions confirm a significant reduction in the bacterium viable population $\geq 80 \%$, in contrast to the other fractions. The fractions were fractionated from extracts with a higher content of glycosylated flavonoids. Although ethyl acetate fractions are fractionated from extracts with higher content of glycosylated flavonoids, the extractive method used results in fractions with higher content of diterpenes in relation to flavonoids, since ethyl acetate is a good solvent to extract clerodan diterpenes (specifically casearins) due to their polarity, so even in extracts with low diterpene content, the content that is present will be extracted, varying only the yield between each resulting fraction (Bueno PCP, unpublished observation). The terpenes may affect the virulence and could be responsible for the bactericidal effect found $[67,69,70]$. Thus, they should now be considered for future studies concerning activity against oral biofilms and anti-Gtfs activity, in addition to the paramount importance of isolating and identifying bioactive compounds from fractions.

Among the mapped phenolic compounds identified in ARA/SP [33], two of them (catechins and quercetins) affect the activity of $S$. mutans Gtf enzymes [71], interfering with the synthesis of soluble and insoluble glucans in biofilms [72, 73]. Moreover, quercetin has inhibitory 
activity against bacterial acid production [74, 75]. This anti-Gtfs action described for the phenols also found in C. sylvestris may be indirectly responsible for the biomass decrease observed for treated $S$. mutans biofilms. Here, the extracts with promising antimicrobial and antibiofilm activities against $S$. mutans also inhibited GtfB activity. The anti-Gtfs effect may reduce the quantity of exopolysaccharides and may cause both the reduction of the overall biofilm volume and affect bacterial biomass, as observed here. This cascade of events would limit the binding sites available for adhesion and bacterial co-aggregation, interfering in the initial stage of biofilm formation. Another effect on Gtfs activity would be the modification of glucans produced, in which the type of glycosidic linkage could be affected. Changes in the type of and proportions of glycosidic linkages and ramifications can hinder biofilm build-up by weakening the binding of microbial cells and the overall tridimensional structure of biofilms [5].

The simultaneous presence of flavonoids and diterpenes compounds in $\mathrm{FLO} / \mathrm{SC}, \mathrm{GUA} / \mathrm{SP}, \mathrm{PAC} / \mathrm{CE}$, and $\mathrm{PRE} / \mathrm{SP}$ can be particularly advantageous concerning the other extracts, as previous studies show that phenols and terpenes are effective against $S$. mutans $[58,60,61]$. Thus, here, FLO/SC, GUA/CE, and PRE/SP affected the activity of GtfB and caused a decrease in the amount of glucans produced. However, $\mathrm{FLO} / \mathrm{SC}, \mathrm{PAC} / \mathrm{CE}$, and PRE/SP extracts may have also affected the quality of glucans formed by GtfB, since a larger number of $S$. mutans cells were removed after adhesion to glucans when these extracts were present during their synthesis. Therefore, the four extracts from the Atlantic Forest, var. sylvestris could modify the glucans formed on the sHA surfaces, and this modification could weaken the adhesion of $S$. mutans to the initial glucan matrix. Insoluble glucans are virulence markers of cariogenic biofilms $[5,56]$; thus, interfering with this trait is an approach to prevent dental caries. This behavior is clinically desirable because it could facilitate the mechanical removal of cells when using a formulation with these extracts in the future. In contrast, these four extracts did not modify the salivary pellicle, since no extract significantly affected the removal of cells adhered to the salivary pellicle.

Clerodane-type diterpenes are secondary metabolites of the terpene class, a class to which the diterpenes of the extracts belong. This class of compounds has been identified as responsible for the activity on C. albicans. Terpenes act on the permeability of fungal cells causing changes in membrane properties and their functions [76-79], cell morphology, and inhibit the growth of this fungus. Tannins (phenolic substance) are bioactive compounds of C. sylvestris [80] that inhibited in vitro yeast growth and inactivated the fungal cell membrane by precipitating proteins [81]. These bioactive compounds may be related to the results obtained after treatments of $C$. albicans with PAC/CE and PRE/SP. In addition, although RIO/RS and SRM/MG showed a statistically significant reduction in the biofilm population of $C$. albicans, how far this reduction is biologically significant needs to be investigated because of the data high variability. Both RIO/RS and SRM/MG presented predominantly glycosylated flavonoids, suggesting that these phenolic compound act better when in association with diterpene compounds in the extract, as found for PAC/ $\mathrm{CE}$ and PRE/SP, probably due to an action of some component(s) that increases the stability or bioavailability of the other or increasing its metabolism [82]. Moreover, the lack of effect of extracts on biomass reduction of $C$. albicans biofilms can be attributed to the morphological difference between the tested microorganisms, since one is a Gram-positive bacterium while the other is a fungus.

Here, extracts of $C$. sylvestris were more active against $S$. mutans compared to the effects against C. albicans, both in antimicrobial and antibiofilm analyses. C. albicans has several virulence factors, such as polymorphism [influenced by quorum sensing signaling molecules tyrosol, a phenylethanoid (yeast to hyphae) and farnesol, a sesquiterpene (hyphae to yeast)], biofilm formation (presence of extracellular matrix), and control of nutrient competition [83, 84]. These are the main factors associated with resistance and drug tolerance and may cause a less pronounced effect of the extracts for this microorganism. In addition, the biomass of $C$. albicans after the treatments showed high variability and this behavior was not reported in previous studies, but it could be related both to the virulence factors of the microorganism and to the variability of the antifungal activity within the same extract [84].

The extracts PRE/SP, GUA/CE, MOG/SP, SRM/MG, ARA/SP, and V control inhibited about $25 \%$ of cell viability, thus, exerting slight cytotoxicity to the oral keratinocytes. However, two extracts caused moderate cytotoxicity (PAC/CE and FLO/SC). Nevertheless, because all extract treatments and V caused cell death, the cytotoxic effect observed is mostly associated with the concentration of ethanol and DMSO used in the vehicle. Therefore, the reduction of the concentration of ethanol and DMSO should be considered for further studies. Furthermore, the two treatments that were moderately cytotoxic (PAC/CE and FLO/SC) could have antimicrobial and antibiofilm activities because of the toxicity observed in the cytotoxicity assay. Also, the methodology of MTT has its limitations [85], because the oral mucosa is a tissue with three-dimensional organization and not monolayer cells, and therefore toxicity studies should be performed using in vivo models and even more than one assay should be used to determine cell viability in vitro studies, as this would increase the reliability of the 
results obtained. Moreover, a reduction in the cytotoxicity of these extracts could be achieved by isolating the active fraction from the crude extract, which should be better evaluated, and/or decreasing the concentration of $\mathrm{EtOH}$ and DMSO in the vehicle.

Caution is required in interpreting the data presented to avoid overestimation of the effects for the control of cariogenic biofilms. Here, simple models were used to verify which extracts have potential antimicrobial and/or antibiofilm activities (which usually employ an exposure time of $24 \mathrm{~h}$ during screenings [38]) and evaluated those that had an inhibitory outcome also for cytotoxic effect against oral keratinocytes organized in monolayers after $1 \mathrm{~h}$ exposure (which do not mimic the complex organization of the oral mucosa tissue). Moreover, to test further the effect of selected extracts with 'promising' antibiofilm activity, we used models for GtfB activity and $S$. mutans adhesion to treated pellicle with exposure time of $30 \mathrm{~min}$, while for microbial adhesion to glucan matrix, the treatments were present for $4 \mathrm{~h}$ (which are the exposure times established in the literature) [11, 12, $39,40]$. As described above, the next step of this line of research, in addition to using optimized concentrations of the extracts, will be to evaluate the extracts and AcOEt fractions using more complex models with shorter exposure time to mimic a clinical application.

The content of flavonoids and diterpenes could be standardized in extracts and promising fractions, overcoming problems of compositional variation associated with phytochemical extraction and geographic or seasonal influences. It is noteworthy that because C. sylvestris flourishes and grows fruit in the second year of life [86] and lives at least 20 years [87], cultivation is favorable for therapeutic purposes. Also, its wood can be used as fuel and for the construction of fences, posts, stakes, rustic carpentry, and cable tools [87]. Therefore, the controlled cultivation of C. sylvestris may contribute to the development of new agents for the control of cariogenic biofilm, which reduces the final cost when compared to the purified compounds. Although this study used simplistic in vitro models, the results substantiate the ethnobotanical use of extracts and fractions of specific biomes and varieties for the prevention of oral cariogenic biofilms. However, in vitro data from more complex (e.g., microcosm) and in vivo models may be useful in determining the potential utility of this plant.

\section{Conclusions}

Specific extracts and fractions of C. sylvestris are effective in inhibiting pathogenic microorganisms related to dental caries and are therefore promising candidates for the development of a dental caries preventive formulation.

\section{Abbreviations}

DMSO: Dimethyl sulfoxide; EtOH: Ethanol; $\mathrm{IC}_{50}$ : the inhibitory concentration of the extract or fraction that inhibits growth of the microorganisms by 50\%; TYE: Tryptone yeast extract; TYEg: Tryptone yeast extract with glucose; TYEs: Tryptone yeast extract with sucrse; V: Vehicle; var: variety

\section{Acknowledgements}

The authors would like to thank the volunteer who donated saliva for this study, Bruna Natália Alves da Silva Pimentel and Dr. Paula Aboud Barbugli for technical support for keratinocytes cultivation and cytotoxicity assay, and Dr. Roseli B. Torres for identity confirmation and variety assignment of $C$. sylvestris.

\section{Authors' contributions}

Conceived and designed the experiments: AJC, PCPB, MIK. Preparation and fractionation of the plant extracts: PCPB, KC, AAF, AJC. Carried out the experiments: SMR, EDOF, MIK. Analysed the data: SRM, PCPB, MIK. Reagents / materials / analysis tools: AJC, MIK. Wrote the paper: SMR, MIK. All authors read and approved the final manuscript.

\section{Funding}

This research was supported by a research grant from the São Paulo Research Foundation (FAPESP \#2013/07600-3 to AJC) and scholarships plus overhead funds (FAPESP \#2017/07408-6 to SMR; \#2011/21440-3 and \#2012/ 21921-4 to P(PB). The National Council for Scientific and Technological Development in association with FAPESP provided additional support (INCT CNPq \#465637/2014-0 and FAPESP \#2014/50926-0 to AJC). The funding body had no role in the design of the study or collection, analysis, and interpretation of data and in writing the manuscript.

\section{Availability of data and materials}

Data sets generated during and/or analysed during the current study are available from the corresponding authors upon reasonable request.

\section{Ethics approval and consent to participate}

All potential volunteers received an explanation about the study and consented to donated saliva for pellicle formation by signing an informed consent term. One volunteer participated in this study. The study was approved by the Institutional Ethical Committee at São Paulo State University (Unesp), School of Dentistry, Araraquara. (CAAE: 68161417.0.0000.5416).

\section{Consent for publication}

"Not applicable". Saliva samples were collected without volunteer identification.

\section{Competing interests}

The authors declare that they have no competing interests.

\section{Author details}

${ }^{1}$ Department of Dental Materials and Prosthodontics, São Paulo State University (UNESP), School of Dentistry, Rua Humaitá, 1680. Araraquara, Sao Paulo 14801-903, Brazil. ²Department of Organic Chemistry, São Paulo State University, Rua Prof. Francisco Degni 55, Araraquara, São Paulo 14800-060, Brazil. ${ }^{3}$ Present address: University of São Paulo (USP), School of Pharmaceutical Sciences, Ribeirão Preto, São Paulo, Brazil.

Received: 19 July 2019 Accepted: 15 October 2019

Published online: 12 November 2019

\section{References}

1. Marcenes W, Kassebaum NJ, Bernabé E, Flaxman A, Naghavi M, Lopez A, Murray CJ. Global burden of oral conditions in 1990-2010: a systematic analysis. J Dent Res. 2013;92(7):592-7.

2. Kassebaum NJ, Bernabé E, Dahiya M, Bhandari B, Murray CJ, Marcenes W. Global burden of untreated caries: systematic review and metaregression. J Dent Res. 2015;94(5):650-8.

3. Kassebaum NJ, Smith AGC, Bernabé E, Fleming TD, Reynolds AE, Vos T, et al. GBD 2015 Oral health collaborators. Global, regional, and National Prevalence, incidence, and disability-adjusted life years for Oral conditions for 195 countries, 1990-2015: a systematic analysis for the global burden of diseases, injuries, and risk factors. J Dent Res. 2017;96(4):380-7. 
4. Marsh PD. Are dental diseases examples of ecological catastrophes? Microbiology. 2003;149(2):279-94.

5. Bowen WH, Koo H. Biology of Streptococcus mutans-derived glucosyltransferases: role in extracellular matrix formation of cariogenic biofilms. Caries Res. 2011;45(1):69-86.

6. Loesche WJ. Role of Streptococcus mutans in human dental decay. Microbiol Rev. 1986;50(4):353-80.

7. Beighton D. The complex oral microflora of high-risk individuals and groups and its role in the caries process. Community Dent Oral Epidemiol. 2005; 33(4):248-55.

8. Kolenbrander PE, Palmer RJ Jr, Periasamy S, Jakubovics NS. Oral multispecies biofilm development and the key role of cell-cell distance. Nat Rev Microbiol. 2010;8(7):471-80

9. Bowen WH, Burne RA, Wu H, Koo H. Oral biofilms: pathogens, matrix, and polymicrobial interactions in microenvironments. Trends Microbiol. 2018; 26(3):229-42.

10. Paes Leme AF, Koo H, Bellato CM, Bedi G, Cury JA. The role of sucrose in cariogenic dental biofilm formation: new insight. J Dent Res. 2006;85(10): 878-87.

11. Vacca-Smith AM, Venkitaraman AR, Schilling KM, Bowen WH. Characterization of glucosyltransferase of human saliva adsorbed onto hydroxyapatite surfaces. Caries Res. 1996;30:354-60.

12. Vacca-Smith AM, Bowen WH. Binding properties of streptococcal glucosyltransferases for hydroxyapatite, saliva-coated hydroxyapatite, and bacterial surfaces. Arch Oral Biol. 1998:43(2):103-10.

13. Shirtliff ME, Peters BM, Jabra-Rizk MA. Cross-kingdom interactions: Candida albicans and bacteria. FEMS Microbiol Lett. 2009;299:1-8.

14. Harriott MM, Noverr MC. Importance of Candida-bacterial polymicrobial biofilms in disease. Trends Microbiol. 2011;19(11):557-63.

15. Jin Y, Samaranayake LP, Samaranayake Y, Yip HK. Biofilm formation of Candida albicans is variably affected by saliva and dietary sugars. Arch Oral Biol. 2004:49:789-98.

16. Falsetta ML, Klein MI, Colonne PM, Scott-Anne K, Gregoire S, Pai CH, et al. Symbiotic relationship between Streptococcus mutans and Candida albicans synergizes the virulence of plaquebiofilms in vivo. Infect Immun. 2014;82: 1968-81.

17. Kim D, Sengupta A, Niepa THR, Lee B-H, Weljie A, Freitas-Blanco VS, et al. Candida albicans stimulates Streptococcus mutans microcolony development via crosskingdom biofilm-derived metabolites. Sci Rep. 2017;7:41332.

18. Sampaio AA, Souza SE, Ricomini-Filho AP, Del Bel Cury AA, Cavalcanti YW, Cury JA. Candida albicans increases dentine demineralization provoked by Streptococcus mutans biofilm. Caries Res. 2019;53(3):322-31.

19. Klinke HT, Pönisch R, Kriegel TM, Klimm HW. Immunohistochemical detection of the Collagenolytic Candida Albicans sap 2 proteinase in caries lesions. Caries Res. 2007:41:287.

20. Klinke HT, Kneist $\mathrm{S}$, de Soet JJ, Kuhlisch E, Mauersberger S, Forster A, Klimm W. Acid production by oral strains of Candida albicans and lactobacilli. Caries Res. 2009;43:83-91.

21. Mattos-Graner RO, Klein MI, Smith DJ. Lessons learned from clinical studies: roles of mutans streptococci in the pathogenesis of dental caries. Curr Oral Health Rep. 2014:1 (1):70-8.

22. ten Cate JM. Novel anticaries and remineralizing agents: prospects for the future. J Dent Res. 2012;91(9):813-5.

23. Freires IA, Rosalen PL. How natural product research has contributed to oral care product development? A critical view. Pharm Res. 2016;33(6):1311-7.

24. Ferreira PMP, Lotufo CVL, Moraes MO, Barro FWA, Martins AMA, Cavalheiro AJ, et al. Folk uses and pharmacological properties of Casearia sylvestris: a medicinal review. Anais Acad Bras Cienc. 2011;83(4):1373-84.

25. Ferreira PMP, Santos DB, Silva JDN, Goudinho AF, Ramos CLS, Souza PC, Almeida RSC, et al. Toxicological findings about an anticancer fraction with casearins described by traditional and alternative techniques as support to the Brazilian Unified Health System (SUS). J Ethnopharmacol. 2019;15:241112004.

26. Hirschmann GS, De Arias AR. A survey of medicinal plants of Minas Gerais. Brazil J Ethnopharmacol. 1990;29(2):159-72.

27. Ruppelt BM, Pereira EF, Gonçalves LC, Pereira NA. Pharmacological screening of plants recommended by folk medicine as anti-snake venom---. Analgesic and anti-inflammatory activities. Mem Inst Oswaldo Cruz. 1991; 86(Suppl 2):203-5.

28. Borges $M M_{\text {, Soares }} \mathrm{AM}$, Rodrigues VM, Andrião-Escarso SH, Diniz $\mathrm{H}$, Hamaguchi A, et al. Effects of aqueous extract of Casearia sylvestris
(Flacourtiaceae) on actions of snake and bee venoms and on activity of phospholipases A2. Comp Biochem Physiol B Biochem Mol Biol. 2000;127(1): 21-30.

29. Tavares WLF, Apolônio ACM, Gomes RT, Teixeira KIR, Brandão MGL, Santos VR. Assessment of the antimicrobial activity of Casearia sylvestris extract against oral pathogenic microorganisms. Rev Cienc Farm Basica Apl. 2008; 29(3):25760.

30. Cavalheiro AH, Godo AP, Carvalho TC, Catirse AB, Furtado NAJC. Antimicrobial potential of Casearia sylvestris against oral bacteria. Rev Odontol UNESP. 2016:45(4):214-8.

31. Xia L, Guo Q, Tu P, Chai X. The genus Casearia: a phytochemical and pharmacological overview. Phytochem Rev. 2015;14:99-135.

32. Claudino JC, Sacramento LV, Koch I, Santos HA, Cavalheiro AJ, Tininis AG, Santos AG. Evaluation of morpho-anatomical and chemical differences between varieties of the medicinal plant Casearia sylvestris Swartz. Anais Acad Bras Cienc. 2013;85(4):1253-65.

33. Bueno PCP, Pereira FMV, Torres RB, Cavalheiro AJ. Development of a comprehensive method for analysing clerodane-type diterpenes and phenolic compounds from Casearia sylvestris Swartz (Salicaceae) based on ultra-high performance liquid chromatography combined with chemometric tools. J Sep Sci. 2015;38:1649-56.

34. Eloff JN. Quantifying the bioactivity of plant extracts during screening and bioassay-guided fractionation. Phytomedicine. 2004;11:370-1.

35. Rios JL, Recio MC. Medicinal plants and antimicrobial activity. J Ethnopharmacol. 2005;100:80-4.

36. Winn DM, Blot WJ, McLaughlin JK, Austin DF, Greenberg RS, Preston-Martin $\mathrm{S}$, Schoenberg JB, Fraumeni JF Jr. Mouthwash use and oral conditions in the risk of oral and pharyngeal cancer. Cancer Res. 1991;51(11):3044-7.

37. Eloff JN. A sensitive and quick microplate method to determine the minimal inhibitory concentration of plant extracts for bacteria. Planta Med. 1998;64:711-4.

38. Saputo S, Faustoferri RC, Quivey RG Jr. A drug repositioning approach reveals that Streptococcus mutans is susceptible to a diverse range of established antimicrobials and nonantibiotics. Antimicrob Agents Chemother. 2018;62(1):e01674-17.

39. Venkitaraman AR, Vacca-Smith AM, Kopec LK, Bowen WH. Characterization of glucosyltransferase B, GtfC, and GtfD in solution and on the surface of hydroxyapatite. J Dent Res. 1995;74:1695-701.

40. Vacca-Smith AM, Venkitaraman AR, Quivey RG Jr, Bowen WH. Interactions of streptococcal glucosyltransferases with alpha-amylase and starch on the surface of saliva-coated hydroxyapatite. Arch Oral Biol. 1996;41(3):291-8.

41. Lemos JA, Abranches J, Koo H, Marquis RE, Burne RA. Protocols to study the physiology of oral biofilms. Methods Mol Biol. 2010;666:87-102.

42. Dubois M, Gilles KA, Hamilton JK, Rebers PA, Smith F. Colorimetric method for determination of sugars and related substances. Anal Chem. 1956;28(3): 350-6.

43. Castilho RM, Squarize CH, Leelahavanichkul K, Zheng Y, Bugge T, Gutkind JS Rac1 is required for epithelial stem cell function during dermal and oral mucosal wound healing but not for tissue homeostasis in mice. PLoS One. 2010;5(5):e10503.

44. Mosmann T. Rapid colorimetric assay for cellular growth and survival: application to proliferation and cytotoxicity assays. J Immunol Methods. 1983;65(1-2):55-63.

45. Vistica DT, Skehan P, Scudiero D, Monks A, Pittman A, Boyd MR. Tetrazolium-based assays for cellular viability: a critical examination of selected parameters affecting formazan production. Cancer Res. 1991;51(10): 2515-20 Erratum in: Cancer Res 1991:51(16):4501.

46. CEN-European Committee for Standardization - Biological evaluation of medical devices: part 5: tests for in vitro cytotoxicity (ISO 10993-5:2009): partie 5: essais concernant la cytotoxicité in vitro (ISO 10993-5:2009). Brussels: CEN; 2009. p.34

47. Bueno PCP, Passareli F, Anhesine NB, Torres RB, Cavalheiro AJ. Flavonoids from Casearia sylvestris Swartz variety lingua (Salicaceae). Biochem Syst Ecol. 2016;68:23-6.

48. Van Dijck P, Sjollema J, Cammue BP, Lagrou K, Berman J, d'Enfert C, et al. Methodologies for in vitro and in vivo evaluation of efficacy of antifungal and antibiofilm agents and surface coatings against fungal biofilms. Microb Cell. 2018:5(7):300-26.

49. Philip N, Bandara HMHN, Leishman SJ, Walsh L. Inhibitory effects of fruit berry extracts on Streptococcus mutans biofilms. Eur J Oral Sci. 2019;127(2): $122-9$. 
50. CLSI. Performance standards for antimicrobial susceptibility testing; twentyfifth informational supplement. CLSI document M100-S25. Wayne, PA: Clinical and Laboratory Standards Institute; 2015.

51. Maltz M, Beighton D. Multidisciplinary research agenda for novel antimicrobial agents for caries prevention and treatment. Adv Dent Res. 2012:24:133-6.

52. Jeon JG, Klein MI, Xiao J, Gregoire S, Rosalen PL, Koo H. Influences of naturally occurring agents in combination with fluoride on gene expression and structural organization of Streptococcus mutans in biofilms. BMC Microbiol. 2009;9:228.

53. Quivey RG Jr, Grayhack EJ, Faustoferri RC, Hubbard CJ, Baldeck JD, Wolf AS, et al. Functional profiling in Streptococcus mutans: construction and examination of a genomic collection of gene deletion mutants. Mol Oral Microbiol. 2015;30(6):474-95.

54. Exterkate RA, Crielaard W, ten Cate JM. Different response to amine fluoride by Streptococcus mutans and polymicrobial biofilms in a novel highthroughput active attachment model. Caries Res. 2010;44:372-9.

55. ten Cate JM. Models and role models. Caries Res. 2015;49:3-10.

56. Hajishengallis E, Parsaei $\mathrm{Y}$, Klein Ml, Koo H. Advances in the microbial etiology and pathogenesis of early childhood caries. Mol Oral Microbiol. 2017;32(1):24-34.

57. Gregoire S, Xiao J, Silva BB, Gonzalez I, Agidi PS, Klein MI, et al. Role of glucosyltransferase B in interactions of Candida albicans with Streptococcus mutans and with an experimental pellicle on hydroxyapatite surfaces. Appl Environ Microbiol. 2011;77(18):6357-67.

58. Jeon JG, Rosalen PL, Falsetta ML, Koo H. Natural products in caries research: current (limited) knowledge, challenges and future perspective. Caries Res. 2011;45(3):243-63.

59. Itokawa H, Totsuka N, Takeya K, Watanabe K, Obata E. Antitumor principles from Casearia sylvestris Sw. (Flacourtiaceae), structure elucidation of new clerodane diterpenes by 2-D NMR spectroscopy. Chem Pharm Bull. 1988; 36(4):1586-8.

60. Morita H, Nakayama M, Kojima H, Takeya K, Itokawa H, Schenkel EP, et al. Structures and cytotoxic activity relationship of casearins, new clerodane diterpenes from Casearia sylvestris Sw. Chem Pharm Bull (Tokyo). 1991;39(3): 693-7.

61. Carvalho PRF, Furlan M, Young MCM, Kingston DGl, Bolzani VS. Acetylated DNA-damaging clerodane diterpenes from Casearia sylvestris. Phytochemistry. 1998;49(6):1659-62

62. Santos AG, Perez CC, Tininis AG, Bolzani VS, Cavalheiro AJ. Clerodane diterpenes from leaves of Casearia sylvestris Swartz. Quim Nova. 2007;30:1100-3.

63. Santos AG, Ferreira PMP, Vieira-Junior GM, Perez CC, Tininis AG, Silva GH, et al. Casearin $\mathrm{X}$, its degradation product and other clerodane diterpenes from leaves of Casearia sylvestris: evaluation of cytotoxicity against normal and tumor human cells. Chem Biodivers. 2010;7(1):205-15.

64. Wang W, Ali Z, Li XC, Khan IA. Clerodane and ent-kaurane diterpene glycosyl and glycoside derivatives from the leaves of Casearia sylvestris. Helv Chim Acta. 2009;92:1829-39.

65. Oberlies NH, Burgess JP, Navarro HA, Pinos RE, Fairchild CR, Peterson RW, et al. Novel bioactive clerodane diterpenoids from the leaves and twigs of Casearia sylvestris. J Nat Prod. 2002;65(2):95-9.

66. Tsuchiya H, Sato M, Miyazaki T, Fujiwara S, Tanigaki S, Ohyama M, et al. Comparative study on the antibacterial activity of phytochemical flavanones against methicillin-resistant Staphylococcus aureus. J Ethnopharmacol. 1996; 50(1):27-34.

67. Koo H, Hayacibara MF, Schobel BD, Cury JA, Rosalen PL, Park YK, et al. Inhibition of Streptococcus mutans biofilm accumulation and polysaccharide production by apigenin and tt-farnesol. J Antimicrob Chemother. 2003;52(5): 782-9.

68. Cowan MM. Plant products as antimicrobial agentes. Clin Microbial Rev. 1999;12(4):564-82.

69. Koo H, Schobel B, Scott-Anne K, Watson G, Bowen WH, Cury JA, Rosalen PL, Park YK. Apigenin and tt-farnesol with fluoride effects on S. mutans biofilms and dental caries. J Dent Res. 2005:84(11):1016-20.

70. Koo H. Strategies to enhance the biological effects of fluoride on dental biofilms. Adv Dent Res. 2008:20(1):17-21.

71. Nakahara K, Kawabata S, Ono H, Ogura K, Tanaka T, Ooshima T, et al. Inhibitory effect of oolong tea polyphenols on glycosyltransferases of mutans streptococci. Appl Environ Microbiol. 1993;59(4):968-73.

72. Hasan S, Singh K, Danisuddin M, Verma PK, Khan AU. Inhibition of major virulence pathways of Streptococcus mutans by quercitrin and deoxynojirimycin: a synergistic approach of infection control. PLoS One 2014;9(3):e91736.

73. Zeng Y, Nikitkova A, Abdelsalam H, Li J, Xiao J. Activity of quercetin and kaemferol against Streptococcus mutans biofilm. Arch Oral Biol. 2019;98:9-16.

74. Duarte S, Gregoire S, Singh AP, Vorsa N, Schaich K, Bowen WH, et al. Inhibitory effects of cranberry polyphenols on formation and acidogenicity of Streptococcus mutans biofilms. FEMS Microbiol Lett. 2006;257:50-6.

75. Gregoire S, Singh AP, Vorsa N, Koo H. Influence of cranberry phenolics on glucan synthesis by glucosyltransferases and Streptococcus mutans acidogenicity. J Appl Microbiol. 2007;103(5):1960-8.

76. Sikkema J, de Bont JA, Poolman B. Mechanisms of membrane toxicity of hydrocarbons. Microbiol Rev. 1995;59(2):201-22.

77. Lambert RJ, Skandamis PN, Coote PJ, Nychas GJ. A study of the minimum inhibitory concentration and mode of action of oregano essential oil, thymol and carvacrol. J Appl Microbiol. 2001;91(3):453-62.

78. Grande-Tovar CD, Chaves-Lopez C, Viuda-Martos M, Serio A, Delgado-Ospina J, Ja P-A, et al. Sub-lethal concentrations of Colombian Austroeupatorium inulifolium (H.B.K.) essential oil and its effect on fungal growth and the production of enzymes. Ind Crop Prod. 2016;87:315-23.

79. Kumar KN, Venkataramana M, Allen JA, Chandranayaka S, Murali HS, Batra $H V$. Role of Curcuma longa L. essential oil in controlling the growth and zearalenone production of Fusarium graminearum. Food Sci Technol. 2016; 69:522-8.

80. Sertie JA, Carvalho JC, Panizza S. Antiulcer activity of the crude extract from the leaves of Casearia sylvestris. Pharm Biol. 2000;38(2):112-9.

81. Vasconcelos LC, Sampaio MC, Sampaio FC, Higino JS. Use of Punica granatum as an antifungal agent against candidosis associated with denture stomatitis. Mycoses. 2003;46(5-6):192-6.

82. Abreu AC, Malheiro ABJ, Simões M. Resurgence of the interest in plants as sources of medicines and resistance-modifying agents. In: Méndez-Vilas A editor. Microbial pathogens and strategies for combating them: science, technology and education. Badajoz: Formatex Research Center; 2013.

83. Lo HJ, Kohler JR, DiDomenico B, Loebenberg D, Cacciapuoti A, Fink R, Nonfilamentous C. albicans mutants are avirulent. Cell Press. 1997;90(5):939-49.

84. Ramage G, Saville SP, Wickes BL, López-Ribot JL. Inhibition of Candida albicans biofilm formation by Farnesol, a quorum-sensing molecule. Appl Environ Microbiol. 2002:68(11):5459-63.

85. Fotakis $\mathrm{G}$, Timbrell JA. In vitro cytotoxicity assays: comparison of $\mathrm{LDH}$, neutral red, MTT and protein assay in hepatoma cell lines following exposure to cadmium chloride. Toxicol Lett. 2006;160(2):171-7.

86. Little EL, Wadsworth FL. Common trees of Puerto Rico and Virgin Islands. Washington: Department of Agriculture; 1964. p. 548

87. Torres RB, Yamamoto K. Taxonomia das espécies de Casearia Jacq. (Flacourtiaceae) do estado de São Paulo. Rev Bras Bot. 1986:9:239-58.

\section{Publisher's Note}

Springer Nature remains neutral with regard to jurisdictional claims in published maps and institutional affiliations.
Ready to submit your research? Choose BMC and benefit from:

- fast, convenient online submission

- thorough peer review by experienced researchers in your field

- rapid publication on acceptance

- support for research data, including large and complex data types

- gold Open Access which fosters wider collaboration and increased citations

- maximum visibility for your research: over $100 \mathrm{M}$ website views per year

At $\mathrm{BMC}$, research is always in progress.

Learn more biomedcentral.com/submissions 